ARTICLE

DOI: $10.1038 / 541467-018-06457-x$

\title{
Pressure tuning of charge ordering in iron oxide
}

\author{
Sergey V. Ovsyannikov (1) 1,2, Maxim Bykov (1) 1, Elena Bykova (1) 1,3, Konstantin Glazyrin², \\ Rudra Sekhar Manna (10) 4, Alexander A. Tsirlin ${ }^{5}$, Valerio Cerantola1,6, llya Kupenko6,7, Alexander V. Kurnosov' \\ Innokenty Kantor 6,8, Anna S. Pakhomova ${ }^{3}$, Irina Chuvashova (1) ${ }^{1}$, Aleksandr I. Chumakov (i) 6, Rudolf Rüffer ${ }^{6}$, \\ Catherine McCammon (iD ${ }^{1} \&$ Leonid S. Dubrovinsky ${ }^{1}$
}

A Verwey-type charge-ordering transition in magnetite at $120 \mathrm{~K}$ leads to the formation of linear units of three iron ions with one shared electron, called trimerons. The recentlydiscovered iron pentoxide $\left(\mathrm{Fe}_{4} \mathrm{O}_{5}\right)$ comprising mixed-valent iron cations at octahedral chains, demonstrates another unusual charge-ordering transition at $150 \mathrm{~K}$ involving competing formation of iron trimerons and dimerons. Here, we experimentally show that applied pressure can tune the charge-ordering pattern in $\mathrm{Fe}_{4} \mathrm{O}_{5}$ and strongly affect the ordering temperature. We report two charge-ordered phases, the first of which may comprise both dimeron and trimeron units, whereas, the second exhibits an overall dimerization involving both the octahedral and trigonal-prismatic chains of iron in the crystal structure. We link the dramatic change in the charge-ordering pattern in the second phase to redistribution of electrons between the octahedral and prismatic iron chains, and propose that the average oxidation state of the iron cations can pre-determine a charge-ordering pattern.

\footnotetext{
${ }^{1}$ Bayerisches Geoinstitut, Universität Bayreuth, Universitätsstrasse 30, D-95447 Bayreuth, Germany. ${ }^{2}$ The Institute for Solid State Chemistry, Russian Academy of Sciences, Urals Division, 91 Pervomayskaya Str., Yekaterinburg 620990, Russia. ${ }^{3}$ Deutsches Elektronen-Synchrotron (DESY), D-22603 Hamburg, Germany. ${ }^{4}$ Department of Physics, IIT Tirupati, Tirupati 517506, India. ${ }^{5}$ Experimental Physics VI, Center for Electronic Correlations and Magnetism, Institute of Physics, University of Augsburg, 86135 Augsburg, Germany. ${ }^{6}$ ESRF-The European Synchrotron, CS40220, 38043 Grenoble Cedex 9, France. ${ }^{7}$ Institut für Mineralogie, Universität Münster, Corrensstraße 24, D-48149 Münster, Germany. ${ }^{8}$ Department of Physics, Technical University of Denmark, 2800 Kgs. Lyngby, Denmark. Correspondence and requests for materials should be addressed to

S.V.O. (email: sergey.ovsyannikov@uni-bayreuth.de)
} 
ron oxides, composed of two of the most abundant elements in the Earth's interior, are fundamentally important materials both for basic science and applied technologies ${ }^{1}$. The first-known magnetic mineral, magnetite $\left(\mathrm{Fe}_{3} \mathrm{O}_{4}\right)$, was the only simple mixedvalent iron oxide known until recently, and for this reason it is a key model system for investigation of $\mathrm{Fe}^{2+} / \mathrm{Fe}^{3+}$ interplay and related physical phenomena. It was discovered that at $120 \mathrm{~K}$ magnetite exhibits an abrupt transition of a metal-insulator-type (the so-called Verwey transition), which is supposed to result from enigmatic charge ordering at the octahedral sites of its cubic spinel structure ${ }^{2}$. Numerous studies were aimed to comprehend the nature and mechanisms of this transition ${ }^{3}$. Only recently, the elusive chargeordering pattern in the Verwey phase of magnetite below $120 \mathrm{~K}$ was finally solved by means of single crystal X-ray diffraction, and a novel type of quasi-particle consisting of linear units of three iron ions with one shared electron, called a trimeron, was proposed ${ }^{4,5}$. This charge ordering is highly unusual and implies a more intricate underlying phenomenon ${ }^{6-8}$ than ordering of separate $\mathrm{Fe}^{2+}$ and $\mathrm{Fe}^{3+}$ ions that takes place, for example, in $\mathrm{TbBaFe}_{2} \mathrm{O}_{5}{ }^{9,10}$ or charge ordering during the course of charge disproportionation ${ }^{11}$.

It was commonly thought that all of the simplest iron oxides fall within three basic stoichiometries, such as $\mathrm{FeO}, \mathrm{Fe}_{3} \mathrm{O}_{4}$, and $\mathrm{Fe}_{2} \mathrm{O}_{3}$. A recent series of high-pressure high-temperature (HPHT) studies using single crystal X-ray diffraction methods discovered and identified a number of novel iron oxides, e.g., $\mathrm{Fe}_{4} \mathrm{O}_{5}{ }^{12,13}, \mathrm{Fe}_{5} \mathrm{O}_{6}{ }^{14,15}, \mathrm{Fe}_{13} \mathrm{O}_{19}{ }^{16}, \mathrm{Fe}_{5} \mathrm{O}_{7}{ }^{17}, \mathrm{Fe}_{25} \mathrm{O}_{32}{ }^{17}, \mathrm{FeO}_{2}{ }^{18-21}$, $\mathrm{Fe}_{7} \mathrm{O}_{9}^{22}$, and a new monoclinic polymorph of $\mathrm{Fe}_{2} \mathrm{O}_{3}$ which can be stable at ambient conditions ${ }^{23}$. Some of the novel oxides, like $\mathrm{Fe}_{4} \mathrm{O}_{5}, \mathrm{Fe}_{5} \mathrm{O}_{6}$, and $\mathrm{Fe}_{7} \mathrm{O}_{9}$, were also found to be readily recoverable at ambient conditions. These discoveries open a portal to mixed-valent iron oxides and motivate investigation of their physical properties and potential for emergent innovative applications. $\mathrm{Fe}_{4} \mathrm{O}_{5}$ can be synthesized at moderate $\mathrm{HP}-\mathrm{HT}$ conditions of about $10 \mathrm{GPa}$ and $1000{ }^{\circ} \mathrm{C}$ and has appeared to be the most common of the above high-pressure iron oxides. It crystallizes in an orthorhombic $\mathrm{CaFe}_{3} \mathrm{O}_{5}$-type structure, one of the known Caferrite $\left(\mathrm{CaFe}_{n}^{2+} \mathrm{Fe}_{2}^{3+} \mathrm{O}_{4+n}, n=1,2\right.$, 3, etc.) phases ${ }^{24,25}$, and this fact could explain the phase and chemical stability of $\mathrm{Fe}_{4} \mathrm{O}_{5}$ and its derivatives, $(\mathrm{M}, \mathrm{Fe}){ }_{2} \mathrm{Fe}_{2} \mathrm{O}_{5}(\mathrm{M}-\mathrm{Mg}, \mathrm{Cr}, \mathrm{Mn})^{26-31}$ at ambient conditions. The crystal structure of $\mathrm{Fe}_{4} \mathrm{O}_{5}$ comprises chains of both trigonal prisms Fe1 (this crystallographic position is denoted here as $\mathrm{Fe} 1$ ) with shared triangular faces, occupied by $\mathrm{Fe}^{2+}$ cations, and an octahedral network occupied by mixed $\mathrm{Fe}^{2+} / \mathrm{Fe}^{3+}$ cations and consisting of (i) single chains of octahedra sharing opposite edges (this crystallographic position is denoted here as $\mathrm{Fe} 2$ ), and (ii) double chains of octahedra composed of two chains similar to the above Fe2 ones, but attached together side-by-side via two other octahedron edges (this crystallographic position is denoted here as $\mathrm{Fe} 3)^{12}$. Like magnetite, $\mathrm{Fe}_{4} \mathrm{O}_{5}$ shows a chargeordering transition below $150 \mathrm{~K}$ involving the competing formation of iron trimers and dimers (two Fe ions with one shared electron) at the octahedral network ${ }^{32}$. It is interesting to note that a recent study identified coexisting trigonal and dimer-like charge ordering patterns in layered $\alpha-\mathrm{RuCl}_{3}{ }^{33}$.

In this work, we synthesize high-quality single crystals of $\mathrm{Fe}_{4} \mathrm{O}_{5}$ and investigate the effect of high pressure on charge ordering in $\mathrm{Fe}_{4} \mathrm{O}_{5}$ at low temperature using single crystal X-ray diffraction, Mössbauer spectroscopy, and magnetization measurements. We find that cold compression of $\mathrm{Fe}_{4} \mathrm{O}_{5}$ stimulates electron transfer between iron cations of different coordination and leads to the formation of novel charge-ordered phases.

\section{Results}

Phase III and two options for its crystal structure. In all experiments, we start from normal conditions $\left(\mathrm{Fe}_{4} \mathrm{O}_{5}-\mathrm{I}\right.$ phase)
(Figs. 1a and 2) and gradually decrease the temperature in the cryostat. At about $200 \mathrm{~K}$ and $2 \mathrm{GPa}$, we observe the appearance of weak and blurred superlattice reflections, indicating the emergence of scattered fragments of a charge-ordering pattern (Fig. 3b). With further temperature decrease and pressure increase, these reflections become progressively stronger and clearer (Fig. 3c). We verify that these reflections do not belong to the earlier-reported charge-ordered $\mathrm{Fe}_{4} \mathrm{O}_{5}$-II phase ${ }^{32}$, and label this phase as $\mathrm{Fe}_{4} \mathrm{O}_{5}$-III. Meanwhile, the presence of $\mathrm{Fe}_{4} \mathrm{O}_{5}$-II is noticeable at 5-7 GPa at the lowest temperature point of $30 \mathrm{~K}$ (Fig. 2). Upon heating at about $18 \mathrm{GPa}$, we can follow the superlattice reflections of $\mathrm{Fe}_{4} \mathrm{O}_{5}$-III up to at least $270 \mathrm{~K}$ (Fig. 2). Thus, pressure strongly enhances the temperature of the chargeordering transition, compared to $150 \mathrm{~K}$ at ambient pressure ${ }^{32}$. We can index the single-crystal diffraction patterns of $\mathrm{Fe}_{4} \mathrm{O}_{5}$-III in either orthorhombic or monoclinic unit cells (Fig. 3d). Eventually, we determine two candidate crystal structures, namely, $\mathrm{Fe}_{4} \mathrm{O}_{5}$-IIIa with a monoclinic $\mathrm{C} 2 / \mathrm{m}$ lattice (Fig. 4) and $\mathrm{Fe}_{4} \mathrm{O}_{5}$-III-b with an orthorhombic $C 222_{1}$ unit cell (Fig. 5), which can equally well fit the experimental X-ray diffraction patterns (Table 1 and Supplementary Table 1). Compared to the original structure $\left(\mathrm{Fe}_{4} \mathrm{O}_{5}-\mathrm{I}\right)$, the crystallographic sites of the iron cations occupying the trigonal prisms in the crystal structures of both $\mathrm{Fe}_{4} \mathrm{O}_{5}$-III-a and $\mathrm{Fe}_{4} \mathrm{O}_{5}$-III-b are split into two slightly non-equivalent $\mathrm{Fe} 1_{-} 1$ and $\mathrm{Fe} 1 \_2$ positions; likewise the octahedral sites $\mathrm{Fe} 2$ and $\mathrm{Fe} 3$ are split into multiple non-equivalent sites, highlighted in different colors in Figs. 4 and 5. Note here that the unusual incommensurately-modulated character of the crystal structure of $\mathrm{Fe}_{4} \mathrm{O}_{5}$-II, reported in previous work ${ }^{32}$, could result from a lattice instability related to competition between the $\mathrm{Fe}_{4} \mathrm{O}_{5}$-III-a and $\mathrm{Fe}_{4} \mathrm{O}_{5}$-III-b phases. A similar type of incommensurability was observed, for example, in the spin-Peierls compound, $\mathrm{TiPO}_{4}{ }^{34,35}$.

In magnetite, the formation of iron trimers in its chargeordered phase is perfectly traced by anomalous shortening of some $\mathrm{Fe}-\mathrm{Fe}$ distances as found by single crystal X-ray diffraction method ${ }^{4}$; hence we also apply this approach to $\mathrm{Fe}_{4} \mathrm{O}_{5}$. The octahedral chains occupied by mixed-valent iron cations show pronounced shortening of distances between some neighboring $\mathrm{Fe}$ atoms; whereas the prismatic chains of iron in both $\mathrm{Fe}_{4} \mathrm{O}_{5}$-III$\mathrm{a}$ and $\mathrm{Fe}_{4} \mathrm{O}_{5}$-III-b structures are characterized by nearly equal
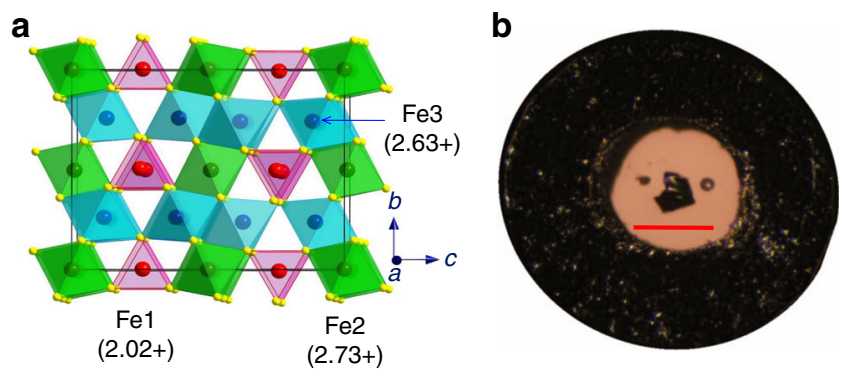

Fig. 1 Crystal structure and image of the $\mathrm{Fe}_{4} \mathrm{O}_{5}$ crystal. a Orthorhombic crystal structure of $\mathrm{Fe}_{4} \mathrm{O}_{5}$ at ambient conditions showing the different crystallographic positions for iron atoms (Fe1, Fe2, and Fe3) in different colors. The bond valence sum values are indicated near the cations. b Image of a single crystal of $\mathrm{Fe}_{4} \mathrm{O}_{5}$ taken through one diamond window. A rhenium gasket of about $40 \mu \mathrm{m}$ thickness with a circular hole of about $150 \mu \mathrm{m}$ diameter drilled in its central part is bridged between the two opposing diamond anvils. The light background color of the central hole is due to light passing through the underlying diamond anvil. The central hole (working area) accommodates the $\mathrm{Fe}_{4} \mathrm{O}_{5}$ single crystal (in the center) and two small pressure markers, Au and ruby, located on the left and right sides of the crystal, respectively. The central hole is filled with a transparent neon pressure-transmitting medium. The scale bar inside the central hole corresponds to $100 \mu \mathrm{m}$ 


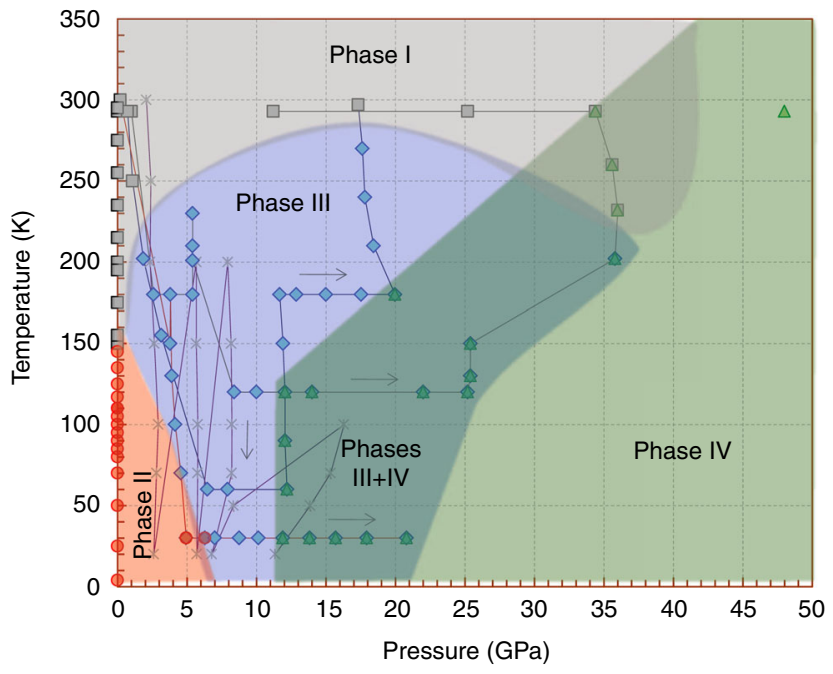

Fig. 2 High-pressure low-temperature phase diagram of $\mathrm{Fe}_{4} \mathrm{O}_{5}$. The diagram is based on the single crystal $\mathrm{X}$-ray diffraction experiments. Experimental points on the diagram corresponding to different phases are shown in different symbols. The shaded areas show the proposed stability regions of the phases. The lines and arrows show the directions of the pressure and temperature variation during the experiments. Since the basic structural reflections of $\mathrm{Fe}_{4} \mathrm{O}_{5}-\mathrm{I}$ and $\mathrm{Fe}_{4} \mathrm{O}_{5}-\mathrm{III}$ structures are identical (Fig. 3), the region of their co-existence could not be properly delineated. One cannot rule out that the region of $\mathrm{Fe}_{4} \mathrm{O}_{5}-\mathrm{III}$ in the phase diagram might be a superposition of stability ranges of $\mathrm{Fe}_{4} \mathrm{O}_{5}-\mathrm{III}-\mathrm{a}$ and $\mathrm{Fe}_{4} \mathrm{O}_{5}-\mathrm{III}-\mathrm{b}$ phases
Fe-Fe distances. For example, at $11.7 \mathrm{GPa}$ and $180 \mathrm{~K}$, the $\mathrm{Fe}-\mathrm{Fe}$ distances in the prismatic chains of the $\mathrm{Fe}_{4} \mathrm{O}_{5}$-III-a structure show a periodicity consisting of one $2.8143 \AA$ and two $2.8176 \AA$ distances; since these two values are very similar, we cannot draw any conclusions about the formation of coupled units in these chains. Compared to the average $\mathrm{Fe}-\mathrm{Fe}$ distance of $\sim 2.8165 \AA$ along the same crystallographic direction ( $b$-axis), the distances between two neighboring octahedrally-coordinated $\mathrm{Fe} 2$ 22 atoms in the single chains of Fe2 octahedra are reduced, to $2.6597 \AA$, and likewise those between Fe3_4 atoms in the double chains of Fe3 octahedra are reduced to $2.7279 \AA$ (Supplementary Table 2). These dramatic shortenings in the distances suggest the formation of dimers (Fig. 4a, c). In the other octahedral chains of this $\mathrm{Fe}_{4} \mathrm{O}_{5}$-III-a phase, equal contractions in two neighboring $\mathrm{Fe}-\mathrm{Fe}$ distances indicate the formation of trimers.

The $\mathrm{Fe}_{4} \mathrm{O}_{5}$-III-b structure exhibits similar features. Its prismatic iron chains show a periodicity in the $\mathrm{Fe}-\mathrm{Fe}$ bond lengths consisting of one $2.8118 \AA$ and two $2.8189 \AA$ distances, where the difference between the two is too small to allow any conclusions about the formation of any bonded units (Fig. 5). In contrast to $\mathrm{Fe}_{4} \mathrm{O}_{5}$-III-a, the $\mathrm{Fe}_{4} \mathrm{O}_{5}$-III-b structure does not contain any trimers (Fig. 5). Both octahedral chains of the $\mathrm{Fe}_{4} \mathrm{O}_{5}$-III-b structure exhibit only dimers with a Fe-Fe bond length of $2.6777 \AA$ in the single chains of $\mathrm{Fe} 2$ octahedra, and $2.7387 \AA$ in the double-chains of $\mathrm{Fe} 3$ octahedra (Supplementary Table 2). Both $\mathrm{Fe}_{4} \mathrm{O}_{5}$-III-a and $\mathrm{Fe}_{4} \mathrm{O}_{5}$-III-b crystal structures show a strong rapprochement between free $\mathrm{Fe} 3$ atoms (Fe3_3 in phase III-a and Fe3_2 in phase III-b, which are unincorporated into the dimer and trimer units) and the neighboring Fe1 atoms in the prisms, which are connected to these Fe3 octahedra via one shared edge (these Fe3-Fe1 pairs are highlighted as white dashed ellipsoids in Figs. 4d and 5d).

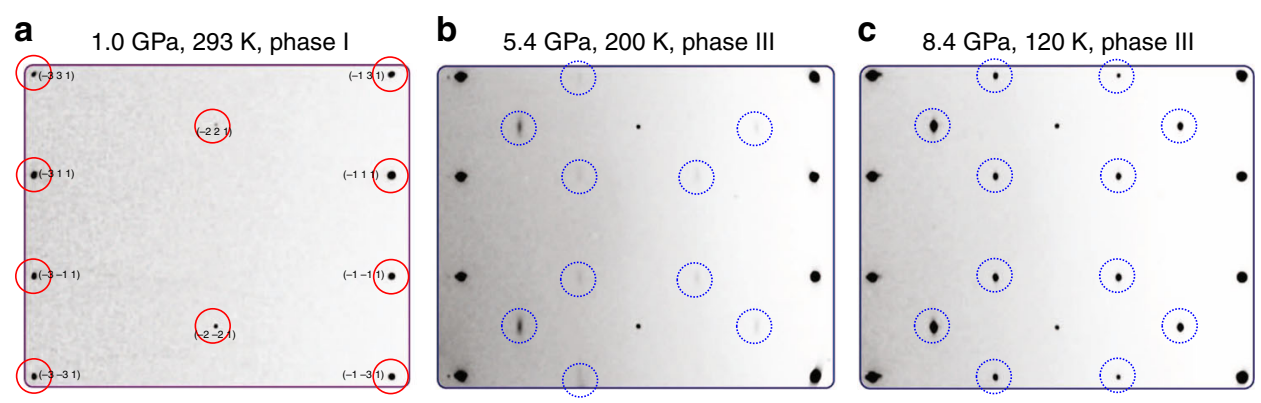

d $\quad 11.7 \mathrm{GPa}, 180 \mathrm{~K}$, phase III

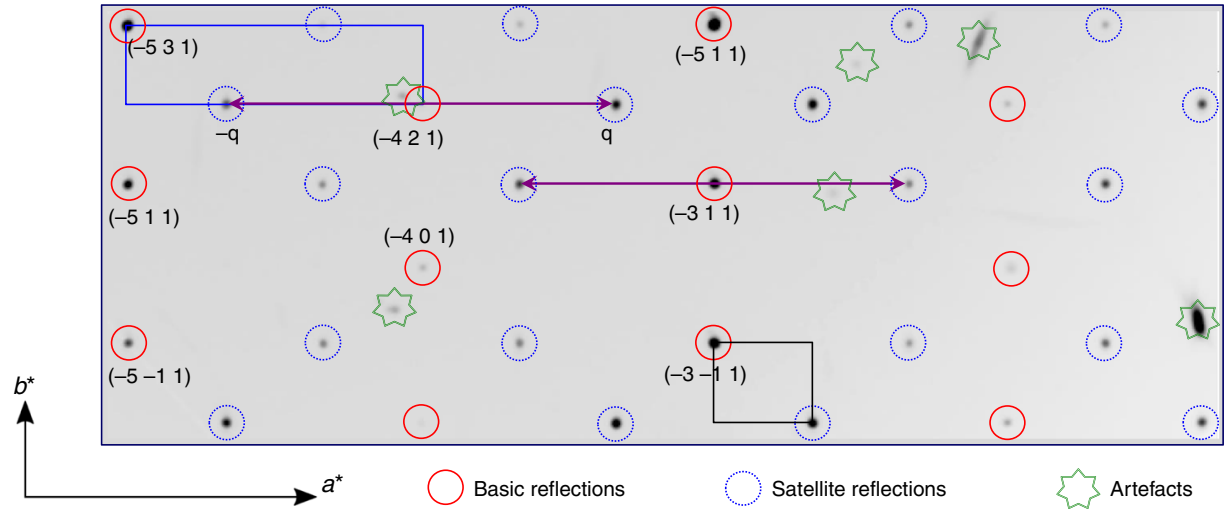

Fig. 3 Examples of reciprocal lattice planes $(h \mathrm{kl})$ of $\mathrm{Fe}_{4} \mathrm{O}_{5}$. These plots correspond to different pressure and temperature conditions (indicated for each plot). a Basic reflections corresponding to the original $\mathrm{Fe}_{4} \mathrm{O}_{5}-\mathrm{I}$ structure, highlighted by red circles. b, $\mathbf{c}$ Emergence of superlattice reflections, highlighted by blue circles (in $\mathbf{b}$ these reflections are rather weak and blurred, but in $\mathbf{c}$ they are strong and clear). $\mathbf{d}$ Reconstruction of (hkl) reciprocal lattice planes, which reveals two possible unit cells of $\mathrm{Fe}_{4} \mathrm{O}_{5}$-III. The first option is an orthorhombic $\mathrm{C}$-centered "average" cell, shown in the upper left corner together with its modulation wave vector $\mathbf{q}\left(\mathrm{Fe}_{4} \mathrm{O}_{5}-\mathrm{III}-\mathrm{b}\right)$. The second option is a $\mathrm{C}$-centered unit cell with a tripled lattice parameter $a$, compared to the average cell $\left(\mathrm{Fe}_{4} \mathrm{O}_{5}-\mathrm{III}-\mathrm{a}\right)$, highlighted at the bottom of the plot 
a

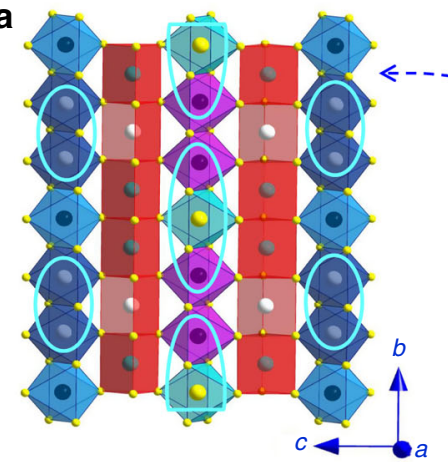

b

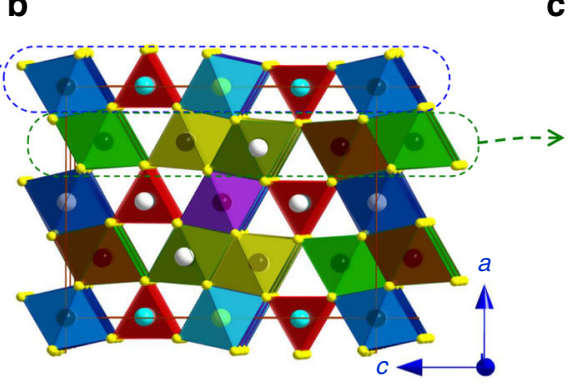

c

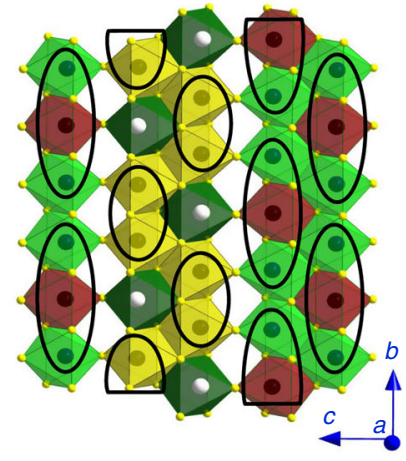

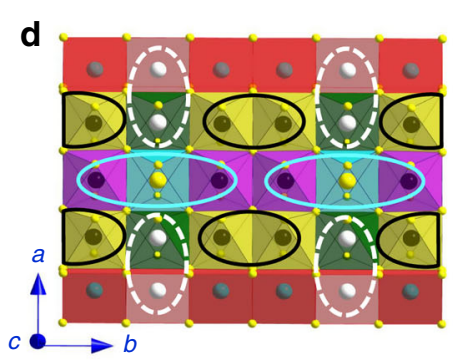

g

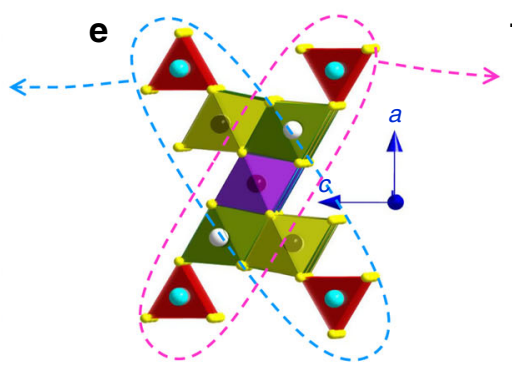

BVS:

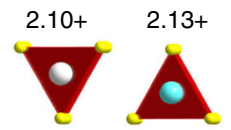

Fe1_1 Fe1_2

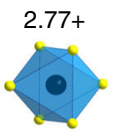

Fe2_1

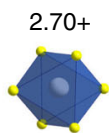

Fe2_2

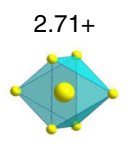

Fe2_3

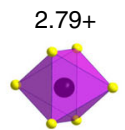

Fe2_4
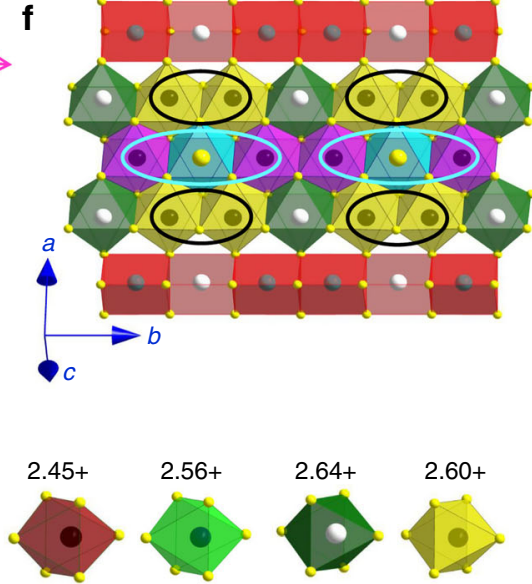

Fe3_1

Fe3_2

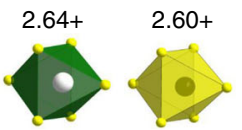

Fe3 $3 \quad F_{3} 4$

Fig. 4 Monoclinic crystal structure of $\mathrm{Fe}_{4} \mathrm{O}_{5}-\mathrm{III}-\mathrm{a}$. This structure has $\mathrm{C} 2 / \mathrm{m}$ symmetry and plots are based on the crystal structure data refined at $11.7 \mathrm{GPa}$ and $180 \mathrm{~K}$. a Projection of the trigonal prisms Fe1 and single chains of Fe2 octahedra. $\mathbf{b}$ The unit cell projected down the $b$-axis. Thin solid lines indicate the unit cell edges. c Projection of the double chains of Fe3 octahedra. d Projection down the c-axis of one of the two diagonal ribbons shown in e. e Two

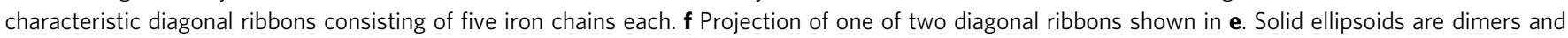
trimers formed in the chains of octahedrally-coordinated iron. Dotted ellipsoids highlight Fe3-Fe1 pairs with shortened Fe-Fe length. Different crystallographic positions are shown in different colors. $\mathbf{g}$ Bond valence sums (BVS) values of all the iron cations in the crystal structure

The Fe-Fe distances in these Fe3-Fel pairs become nearly the same as the average $\mathrm{Fe}-\mathrm{Fe}$ distances in both prismatic and octahedral chains (Supplementary Table 2), thereby suggesting an enhancement of interactions between the iron ions occupying the prisms and octahedra.

We analyze the $\mathrm{Fe}-\mathrm{O}$ bond lengths of all iron cations in both $\mathrm{Fe}_{4} \mathrm{O}_{5}$-III structures using a common bond valence sum (BVS) method (see Experimental Details) ${ }^{36}$. We estimate the average BVS values of the $\mathrm{Fe} 1$ atoms sitting in the prisms as +2.11 and +2.13 in $\mathrm{Fe}_{4} \mathrm{O}_{5}$-III-a and $\mathrm{Fe}_{4} \mathrm{O}_{5}$-III-b structures, respectively. The BVS analysis suggests that the dimers formed at the double chains of $\mathrm{Fe} 3$ octahedra of both structures consist of moderately overcharged valence-mixed $\mathrm{Fe}^{2.5+}$ ions; whereas, the dimers formed at the single-chain $\mathrm{Fe} 2$ octahedra have a charge as high as +5.4 (Figs. 4 and 5). Likewise, this analysis shows that, compared to a combination of one $\mathrm{Fe}^{2+}$ and two $\mathrm{Fe}^{3+}$ ions, the trimers in the $\mathrm{Fe}_{4} \mathrm{O}_{5}$-III-a structure are either strongly overcharged $(+8.29$ for the single chains of $\mathrm{Fe} 2$ octahedra) or strongly undercharged $(+7.57$ for the double chains of $\mathrm{Fe} 3$ octahedra) (Fig. 4).

Phase IV and charge ordering in chains of trigonal prisms. In all three experimental runs at pressures above $12 \mathrm{GPa}$ and temperatures below $150 \mathrm{~K}$, we observe the appearance of additional structural reflections (Supplementary Fig. 1), suggesting the beginning of another transition to a further phase, labeled as $\mathrm{Fe}_{4} \mathrm{O}_{5}$-IV (Fig. 2). Below $150 \mathrm{~K}$ this transition is nearly complete at $25 \mathrm{GPa}$, but at slightly higher temperature $(200 \mathrm{~K})$, minor traces of $\mathrm{Fe}_{4} \mathrm{O}_{5}$-III are still observable even at $36 \mathrm{GPa}$ (Fig. 2). Upon heating to room temperature at $36 \mathrm{GPa}, \mathrm{Fe}_{4} \mathrm{O}_{5}$-IV gradually transforms to the original $\mathrm{Fe}_{4} \mathrm{O}_{5}$-I phase; meanwhile, a noticeable fraction of $\mathrm{Fe}_{4} \mathrm{O}_{5}$-IV persists even at $293 \mathrm{~K}$ (Fig. 2).

The single crystal X-ray diffraction images of $\mathrm{Fe}_{4} \mathrm{O}_{5}$ collected at $25.2 \mathrm{GPa}$ and $120 \mathrm{~K}$ correspond to almost pure $\mathrm{Fe}_{4} \mathrm{O}_{5}-\mathrm{IV}$ (Supplementary Fig. 1), and we determine its monoclinic $P 2_{1} / m$ symmetry and atomic positions. The structure shows an overall dimerization along the $c$-axis involving both octahedral and prismatic chains (Fig. 6). We calculate BVS values of the iron ions in this structure using the above $\operatorname{method}^{36}$, and find an average value for the prismatic Fel atoms of +2.26 . This value deviates from +2 established for these prismatic sites in the original $\mathrm{Fe}_{4} \mathrm{O}_{5}$-I phase $\mathrm{I}^{12,32}$, and taking into account the emergence of dimeric ordering in these chains, we conclude that the prismatic sites in $\mathrm{Fe}_{4} \mathrm{O}_{5}$-IV are filled with mixed-valent iron cations. In the same way, the average BVS values of the iron in the single chains of $\mathrm{Fe} 2$ and double chains of $\mathrm{Fe} 3$ octahedra in $\mathrm{Fe}_{4} \mathrm{O}_{5}$-IV are found as +2.63 and +2.554 , respectively (Fig. 6). These values are also consistent with the dimeric ordering in the chains. These BVS results indicate that $\mathrm{Fe}_{4} \mathrm{O}_{5}$ with a nominal average oxidation state of iron as $\mathrm{Fe}^{2.5+}$ tends to reach a state under pressure with more uniform charge distribution, implying an average oxidation state of $\mathrm{Fe}^{2.5+}$ in all iron chains.

During the $\mathrm{Fe}_{4} \mathrm{O}_{5}$-III $\rightarrow \mathrm{Fe}_{4} \mathrm{O}_{5}$-IV phase transition under increasing pressure, the crystal lattice shrinks noticeably along 
a

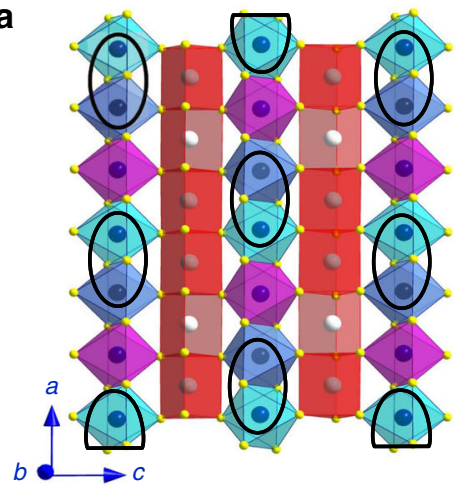

d

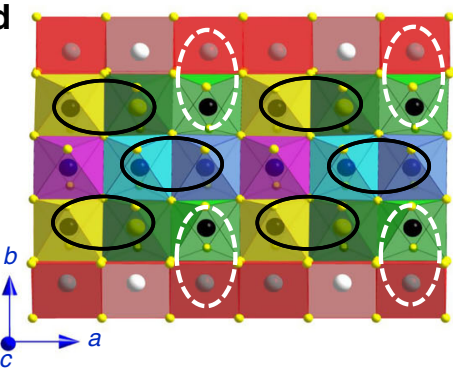

b
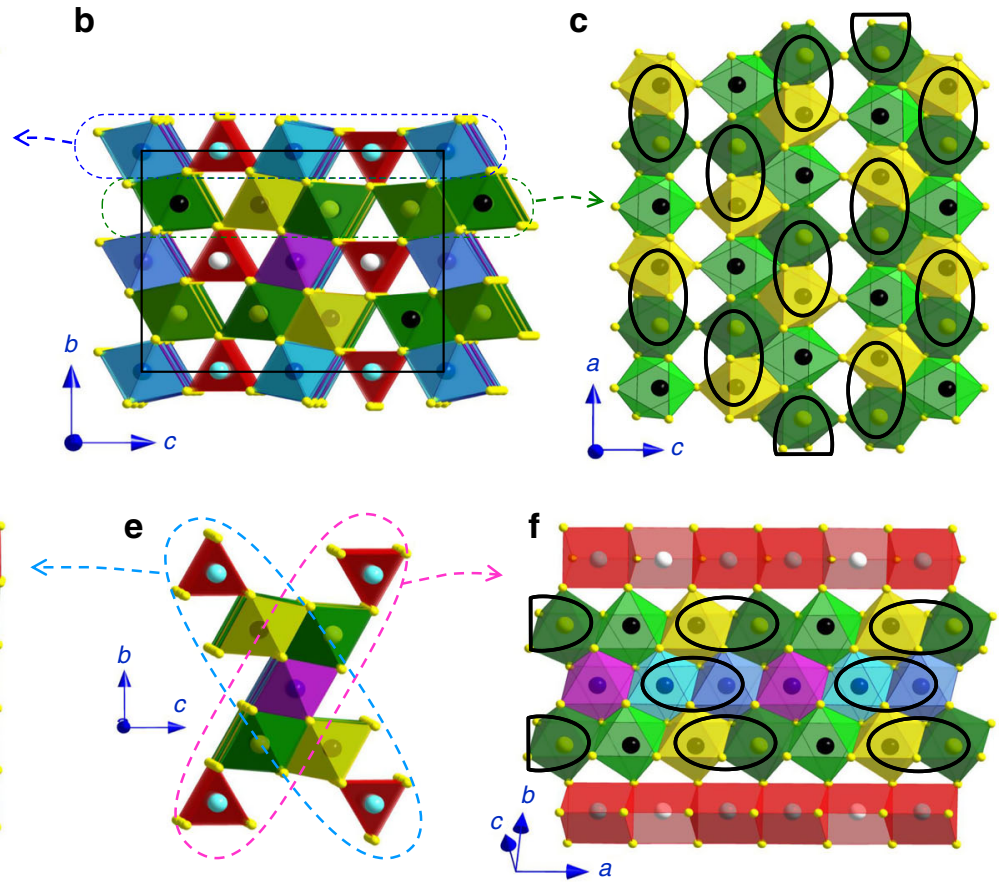

g

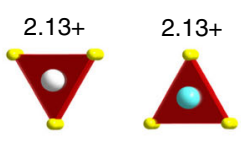

Fe1_1

Fe1_2

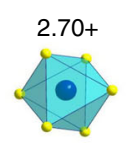

Fe2_1

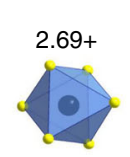

Fe2_2
BVS:

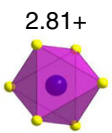

Fe2_3

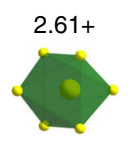

Fe3_1

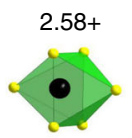

Fe3_2

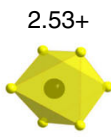

Fe3_3

Fig. 5 Orthorhombic crystal structure of $\mathrm{Fe}_{4} \mathrm{O}_{5}-\mathrm{III}-\mathrm{b}$. The structure has $\mathrm{C}_{22} 22_{1}$ symmetry and plots are based on the crystal structure data refined at $11.7 \mathrm{GPa}$ and $180 \mathrm{~K}$. a Projection of the trigonal prisms Fe1 and single-chains of Fe2 octahedra. $\mathbf{b}$ The unit cell projected down the $a$-axis. Thin solid lines indicate the unit cell edges. c Projection of the double chains of Fe3 octahedra. d Projection down the c-axis of one of the two diagonal ribbons shown in e. e Two characteristic diagonal ribbons consisting of five iron chains each. $\mathbf{f}$ Projection of one of the two diagonal ribbons shown in e. Solid ellipsoids are dimers formed in the chains of octahedrally-coordinated iron. Dotted ellipsoids highlight Fe3-Fe1 pairs with shortened Fe-Fe length. Different crystallographic positions are shown in different colors. $\mathbf{g}$ Bond valence sums (BVS) values of all the iron cations in the crystal structure

Table 1 Unit cell parameters of different phases of $\mathrm{Fe}_{4} \mathrm{O}_{5}$

\begin{tabular}{|c|c|c|c|c|c|}
\hline \multirow[t]{2}{*}{ Details of crystal structures } & \multicolumn{5}{|l|}{ Phases } \\
\hline & $\mathrm{Fe}_{4} \mathrm{O}_{5}-\mathrm{I}$ & $\mathrm{Fe}_{4} \mathrm{O}_{5}-I I I-\mathrm{a}$ & $\mathrm{Fe}_{4} \mathrm{O}_{5}-$ III-b & $\mathrm{Fe}_{4} \mathrm{O}_{5}=\mathrm{IV}(\mathrm{LT})$ & $\mathrm{Fe}_{4} \mathrm{O}_{5}-\mathrm{IV}(\mathrm{HT})^{\mathrm{a}}$ \\
\hline Pressure (GPa) & Ambient & 11.7 & 11.7 & 25.2 & 48 \\
\hline Crystal system & Orthorhombic & Monoclinic & Orthorhombic & Monoclinic & Monoclinic \\
\hline Space group (No.) & Cmcm (No. 63) & C2/m (No. 12) & $\mathrm{C} 222_{1}$ (No. 20) & $P 2_{1} / m($ No. 11$)$ & $P 2_{1} / m$ (No. 11) \\
\hline Lattice parameter, a $(\AA)$ & $2.89200(5)$ & $9.675(4)$ & $8.4492(3)$ & $5.0145(10)$ & $4.9408(10)$ \\
\hline Lattice parameter, $b(\AA)$ & $9.7979(2)$ & $8.4493(3)$ & $9.6750(4)$ & $12.1155(18)$ & $11.7880(18)$ \\
\hline Unit cell volume, $V\left(\AA^{3}\right)$ & $356.54(7)$ & $1007.8(6)$ & $1007.7(6)$ & $317.66(8)$ & 299.33(8) \\
\hline$Z$ & 4 & 12 & 12 & 4 & 4 \\
\hline Calculated density $\left(\mathrm{g} / \mathrm{cm}^{3}\right)$ & 5.65138 & 5.99868 & 5.99875 & 6.34361 & 6.73215 \\
\hline
\end{tabular}

aThis phase appeared after laser heating

the dimerization direction. This leads to a lattice volume collapse by about $0.5 \%$ at $120 \mathrm{~K}$ (Fig. $7 \mathrm{a}$ ). This volume collapse may be attributed to a more homogeneous charge distribution in the $\mathrm{Fe}_{4} \mathrm{O}_{5}$-IV phase, which should lead to a volume contraction. By fitting the third-order Birch-Murnaghan equation of state ${ }^{37,38}$ to the compression data of the $\mathrm{Fe}_{4} \mathrm{O}_{5}$-III phase at $120 \mathrm{~K}$ (Fig. 7a), we determine the unit cell volume as $V_{0}=1063.87 \AA^{3}$ and the bulk modulus as $B_{0}=195.3 \mathrm{GPa}$ for fixed $B^{\prime}{ }_{0}=4$. We analyze the ratios of $\mathrm{Fe}-\mathrm{Fe}$ bond lengths in the dimer units compared to those in the gaps between them $\left(d_{\mathrm{Fe}-\mathrm{Fe}}^{\text {units }} / d_{\mathrm{Fe}-\mathrm{Fe}}^{\mathrm{gap}}\right)$ for $\mathrm{Fe} 1, \mathrm{Fe} 2$, and $\mathrm{Fe} 3$ chains, and values to be $0.93,0.90$, and 0.88 , respectively (Supplementary Table 4). This difference in the $d_{\mathrm{Fe}-\mathrm{Fe}}^{\text {units }} / d_{\mathrm{Fe}-\mathrm{Fe}}^{\mathrm{gap}}$ ratios may be referred to the above average BVS values of Fel, $\mathrm{Fe} 2$, and $\mathrm{Fe} 3$ atoms, which should approximately correspond to their oxidation states. In fact, the shortest iron dimers are formed in the double chains of $\mathrm{Fe} 3$ octahedra with an average BVS value 

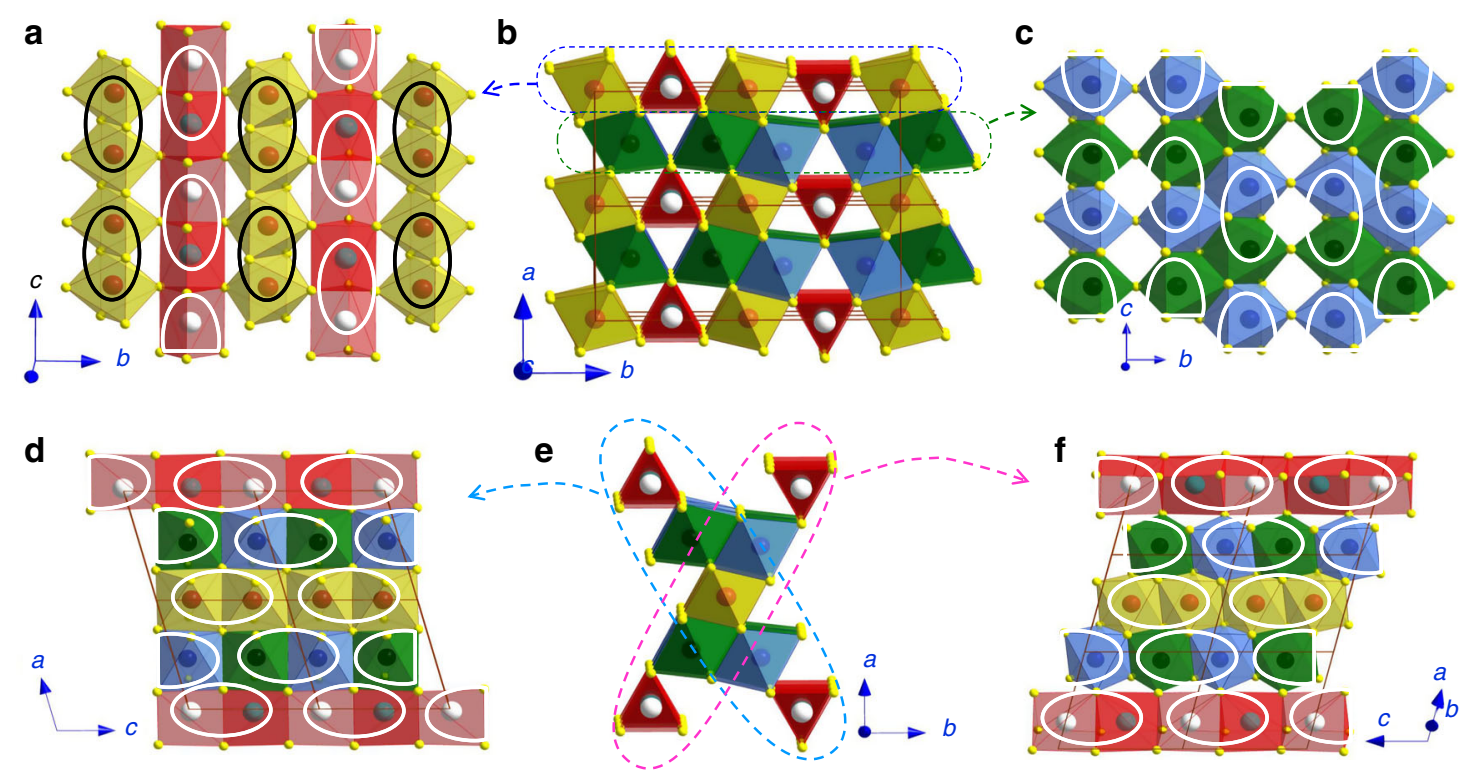

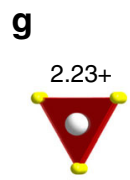

Fe1_1

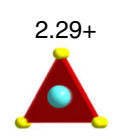

Fe1_2

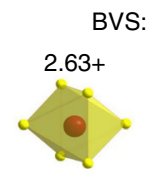

$\mathrm{Fe} 2$

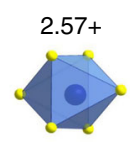

Fe3_1

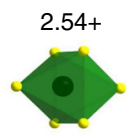

Fe3_2

Fig. 6 Monoclinic crystal structure of $\mathrm{Fe}_{4} \mathrm{O}_{5}-\mathrm{IV}$. The structure has $P 2_{1} / m$ symmetry and plots are based on the crystal structure data refined at 25.2 $\mathrm{GPa}$ and at $120 \mathrm{~K}$. a Projection of the trigonal prisms Fe1 and single chains of Fe2 octahedra. $\mathbf{b}$ Two unit cells projected down the c-axis. Thin solid lines indicate the unit cell edges. c Projection of the double chains of Fe3 octahedra. $\mathbf{d}$ Projection down the $b$-axis of one of the two diagonal ribbons shown in $\mathbf{e}$. e Two characteristic diagonal ribbons consisting of five iron chains each. $\mathbf{f}$ Projection down the $b$-axis of one of the two diagonal ribbons shown in e. Solid ellipsoids are dimers formed in all iron chains. Different crystallographic positions are shown in different colors. $\mathbf{g}$ Bond valence sums (BVS) values of all the iron cations in the crystal structure
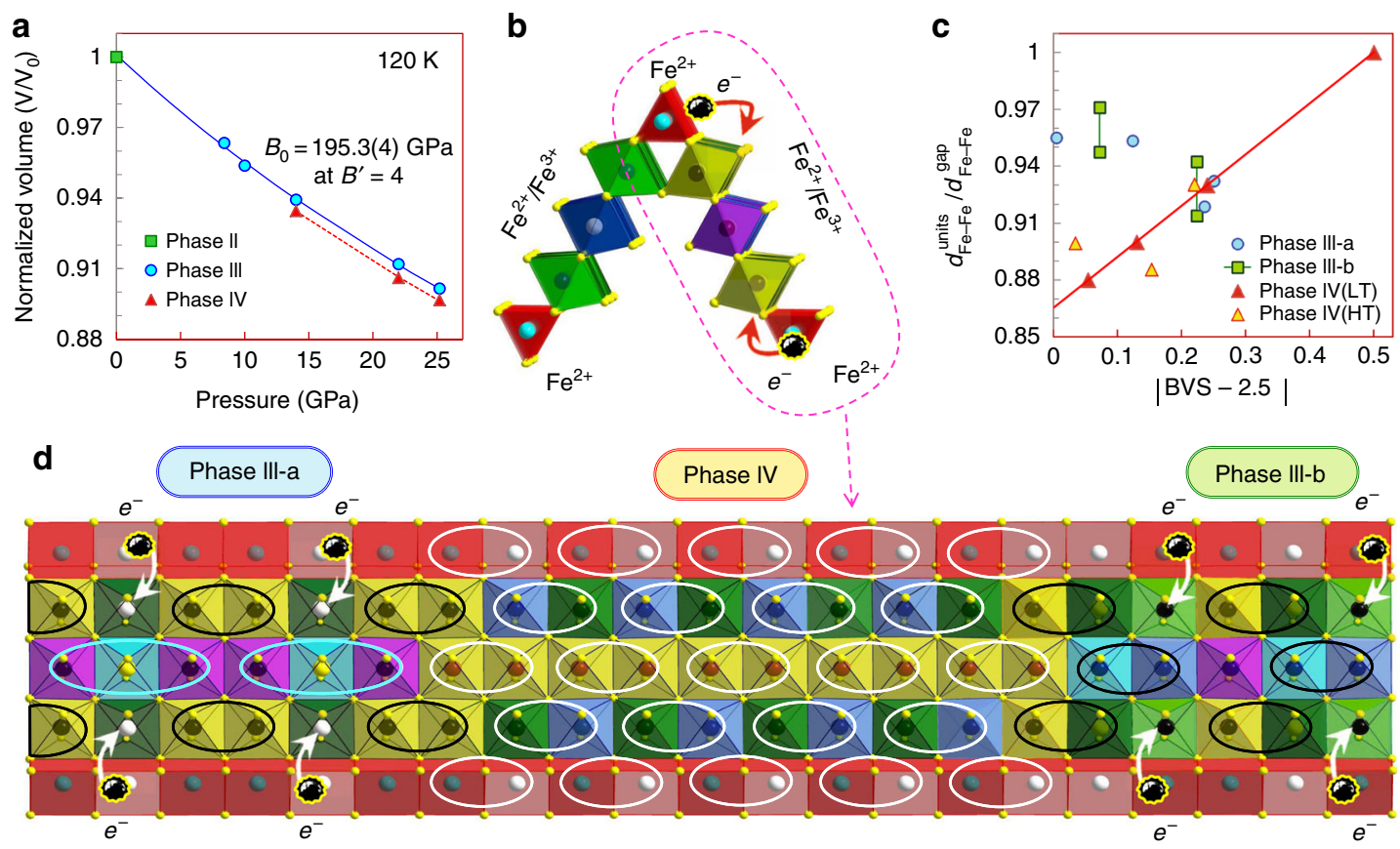

Fig. 7 Pressure-driven $\mathrm{Fe}_{4} \mathrm{O}_{5}-\mathrm{III} \rightarrow \mathrm{Fe}_{4} \mathrm{O}_{5}-\mathrm{IV}$ transition. a Equation of state of $\mathrm{Fe}_{4} \mathrm{O}_{5}$ at $120 \mathrm{~K}$ showing a volume drop of $\sim 0.5 \%$ at the $\mathrm{Fe}_{4} \mathrm{O}_{5}-\mathrm{III} \rightarrow \mathrm{Fe}_{4} \mathrm{O}_{5}-\mathrm{IV}$ transition. $\mathbf{b}$ Edge-shared diagonal ribbons of prisms and octahedra (seen in Figs. 4-6) provide channels for charge hopping between the prisms and octahedra. c Correlation between ratios of Fe-Fe distances in dimers and trimers to those in gaps between them $\left(d_{\mathrm{Fe}-\mathrm{Fe}}^{\text {units }} / d_{\mathrm{Fe}-\mathrm{Fe}}^{\mathrm{gap}}\right)$ and absolute deviations of bond valence sums (BVS) values of iron in these chains from 2.5+. d Model demonstrating the coexistence of several charge-ordered phases in a single crystal of $\mathrm{Fe}_{4} \mathrm{O}_{5}$. The electron transfer from the prisms to octahedra leads to a short-range reorganization of ordering type 
equal to +2.554 , i.e., nearly optimal for the formation of $\mathrm{Fe}^{2+}$ $-\mathrm{Fe}^{3+}$ pairs. In contrast, the longest dimers are formed in $\mathrm{Fe} 1$ prismatic chains with an average BVS value of +2.26 , which deviates the most from +2.5 . Furthermore, we note that the above $d_{\mathrm{Fe}-\mathrm{Fe}}^{\text {units }} / d_{\mathrm{Fe}-\mathrm{Fe}}^{\mathrm{gap}}$ ratios increase linearly with a deviation of their average BVS values from +2.5 , tending to 1 for the limiting case of $\mathrm{Fe}^{2+}$ or $\mathrm{Fe}^{3+}$ (Fig. 7c). This regularity indicates that the resulting length of the dimers is determined by the balance of $\mathrm{Fe}^{2+}$ and $\mathrm{Fe}^{3+}$ cations in each linear chain.

The reduced distances between the free $\mathrm{Fe} 3$ atoms in the doublechains of $\mathrm{Fe} 3$ octahedra and the neighboring $\mathrm{Fe} 1$ atoms in the prisms, observed in both $\mathrm{Fe}_{4} \mathrm{O}_{5}$-III-a and $\mathrm{Fe}_{4} \mathrm{O}_{5}$-III-b structures (highlighted as dashed ellipsoids in Figs. $4 \mathrm{~d}$ and $5 \mathrm{~d}$ ), appear to be the most suitable channels for hopping of electrons from $\mathrm{Fe}^{2+}$ ions occupying Fe1 prisms to the octahedral matrix. Only 1/3 of the Fe1 atoms are involved in these channels, and hence, if the electrons of prismatically-coordinated $\mathrm{Fe}^{2+}$ ions are not delocalized within the framework of these trigonal prismatic chains, the Fel atoms may be maximally charged up to +2.33 on average. The actual BVS values of the two Fel atoms are +2.23 and +2.29 (Fig. 6), which satisfy this constraint well. The coexistence of $\mathrm{Fe}_{4} \mathrm{O}_{5}$-III and $\mathrm{Fe}_{4} \mathrm{O}_{5}$-IV phases over an extended pressure range (Fig. 2) suggests that this phase transition is rather prolonged. Likely, it is caused by the gradual pressure-driven electron transfer from the trigonal prismatic chains to the octahedral ones. The $\mathrm{Fe}_{4} \mathrm{O}_{5}$-III-b structure comprises only dimers; hence having free iron cations in all $\mathrm{Fe} 3$ chains provides twice as many channels for the charge hopping compared to the $\mathrm{Fe}_{4} \mathrm{O}_{5}$-III-a structure.

As mentioned above, we observe that a noticeable fraction of the $\mathrm{Fe}_{4} \mathrm{O}_{5}$-IV phase persists upon heating to $293 \mathrm{~K}$ at $35 \mathrm{GPa}$ (Fig. 2). To examine the possibility of the room-temperature phase transition $\mathrm{Fe}_{4} \mathrm{O}_{5}-\mathrm{I} \rightarrow \mathrm{Fe}_{4} \mathrm{O}_{5}-\mathrm{IV}$, we compress a single crystal of $\mathrm{Fe}_{4} \mathrm{O}_{5}$ in a separate experiment to about $45 \mathrm{GPa}$, but we see no evidence for a phase transition. Previous works also did not find any structural phase transition in this range ${ }^{12,39}$. At the maximum pressure of 45 $\mathrm{GPa}$, we laser-heat the sample up to $2000^{\circ} \mathrm{C}$, and indeed we observe a structural transition to the same dimerized $\mathrm{Fe}_{4} \mathrm{O}_{5}$-IV structure (Fig. 2, Table 1). The unusual thermodynamic stability of the $\mathrm{Fe}_{4} \mathrm{O}_{5^{-}}$ IV phase might be explained by the fact that both $\mathrm{Fe}_{4} \mathrm{O}_{5}$-III-a and $\mathrm{Fe}_{4} \mathrm{O}_{5}$-III-b low-temperature structures have the above-discussed $\mathrm{Fe} 3-\mathrm{Fe} 1$ channels for charge hopping (Figs. 4d and 5d), which should facilitate the $\mathrm{Fe}_{4} \mathrm{O}_{5}$-III $\rightarrow \mathrm{Fe}_{4} \mathrm{O}_{5}$-IV transition; whereas a direct $\mathrm{Fe}_{4} \mathrm{O}_{5}-\mathrm{I} \rightarrow \mathrm{Fe}_{4} \mathrm{O}_{5}$-IV transition and its related redistribution of electrons between the prismatic and octahedral chains might be hindered at room temperature, but triggered at high temperatures. We find that average BVS values ${ }^{36}$ of the iron ions in the hightemperature $\mathrm{Fe}_{4} \mathrm{O}_{5}$-IV (HT) phase are nearly the same as those in the low-temperature $\mathrm{Fe}_{4} \mathrm{O}_{5}$-IV (LT) phase, namely, $+2.24(+2.32)$ for prismatic Fe1_1 (Fe1_2) atoms, and +2.653 and +2.534 for the iron in the single chains of $\mathrm{Fe} 2$ and double chains of $\mathrm{Fe} 3$ octahedra, respectively. Analysis of $d_{\mathrm{Fe}-\mathrm{Fe}}^{\text {units }} / d_{\mathrm{Fe}-\mathrm{Fe}}^{\text {gap }}$ ratios in the $\mathrm{Fe}_{4} \mathrm{O}_{5}-\mathrm{IV}(\mathrm{HT})$ structure shows that they do not follow the linear trend established for the $\mathrm{Fe}_{4} \mathrm{O}_{5}$-IV (LT) structure (Fig. 7c), and hence a distribution of $\mathrm{Fe}^{2+}$ and $\mathrm{Fe}^{3+}$ ions at least at the octahedral sites of $\mathrm{Fe}_{4} \mathrm{O}_{5}-\mathrm{IV}(\mathrm{HT})$ is more random than ordered. It can be that the transition mechanism at high temperature is different, and the dimerization observed could instead result from a Peierls transition ${ }^{40}$ rather than from the formation of electrically-bonded $\mathrm{Fe}^{2+}-\mathrm{Fe}^{3+}$ dimers with a shared electron.

Low-temperature high-pressure phase diagram of $\mathrm{Fe}_{4} \mathrm{O}_{5}$. We find the average BVS values of prismatic $\mathrm{Fe} 1$ atoms in $\mathrm{Fe}_{4} \mathrm{O}_{5}-\mathrm{I}$, $\mathrm{Fe}_{4} \mathrm{O}_{5}$-III-a, $\mathrm{Fe}_{4} \mathrm{O}_{5}$-III-b, and $\mathrm{Fe}_{4} \mathrm{O}_{5}$-IV to be +2.016, +2.11, +2.13 , and +2.26 , respectively (Figs. 4-6). As discussed above, the average $\mathrm{BVS}$ value of +2.26 for $\mathrm{Fel}$ atoms in $\mathrm{Fe}_{4} \mathrm{O}_{5}-\mathrm{IV}$, together with the overall structural dimerization including these Fe1 chains, unambiguously confirm the mixed-valent nature of the iron ions at the prismatic sites in this structure. The minor deviations of the BVS values from +2 for $\mathrm{Fel}$ atoms in the $\mathrm{Fe}_{4} \mathrm{O}_{5^{-}}$ III-a and $\mathrm{Fe}_{4} \mathrm{O}_{5}$-III-b phases do not allow us either to conclude a small shift in the oxidation state of these ions toward +3 or to rule that out. The co-existence of $\mathrm{Fe}_{4} \mathrm{O}_{5}$-III and $\mathrm{Fe}_{4} \mathrm{O}_{5}$-IV phases for an extended pressure range (Fig. 2) hints that this transition may follow the electron transfer between the octahedral and prismatic chains. This leads to a short-order reorganization of the charge-ordering pattern and the formation of inclusions of the novel structural order. Comparing the different charge-ordered patterns in $\mathrm{Fe}_{4} \mathrm{O}_{5}-\mathrm{II}^{32}, \mathrm{Fe}_{4} \mathrm{O}_{5}$-III-a, $\mathrm{Fe}_{4} \mathrm{O}_{5}$-III-b, and $\mathrm{Fe}_{4} \mathrm{O}_{5}-\mathrm{IV}$ (Figs. 4-6), we conclude that the average oxidation state of octahedrally-coordinated cations predetermines which ordering type would be optimal. For example, in order to form short trimers, the average oxidation state of iron should be $\sim+2.7$ (Fig. 7c). A moderate decrease in this BVS value leads to the formation of more loosely-bonded long trimers and dimers. For BVS values tending toward +2.5 , a closely-packed dimeric order becomes preferable (Fig. 6). Thus, the average oxidation state of iron ions at the octahedral chains apparently pre-determines an optimal charge-ordering scheme. One can expect, for example in the newly-discovered $\mathrm{Fe}_{7} \mathrm{O}_{9}$ and $\mathrm{Fe}_{5} \mathrm{O}_{6}$ crystallizing in similar structures $^{14,22}$, that the former with a nominal oxidation state of the octahedral ions of +2.8 at ambient pressure is prone to the formation of exclusively trimers; likewise, the latter in which their oxidation state is +2.5 is prone to dimer formation only. A pressure-stimulated electron transfer from the prismatic to octahedral chains can occur inhomogeneously in the bulk of the $\mathrm{Fe}_{4} \mathrm{O}_{5}$ crystal and this can result in the formation of an anomalous charge-ordering pattern combining different co-existing ordering schemes (Fig. 7d).

The process of electron transfer in $\mathrm{Fe}_{4} \mathrm{O}_{5}$ from the trigonal prismatic to the octahedral iron chains towards charge equalization is perhaps not complete by $40 \mathrm{GPa}$, and with further pressurization the average BVS values of all iron cations can probably approach +2.5 even more closely. However, this could hardly change the dimeric charge-ordering pattern of $\mathrm{Fe}_{4} \mathrm{O}_{5}-\mathrm{IV}$ (Fig. 6), unless the material was to become metallic and the charge-ordering state suppressed; although the lattice symmetry may be sensitive to the charge balance. We propose that such electron transfer processes under pressure could also occur in other iron oxides crystallizing in kindred lattices, like the abovementioned $\mathrm{Fe}_{5} \mathrm{O}_{6}{ }^{14}$ and $\mathrm{Fe}_{7} \mathrm{O}_{9}{ }^{22}$. However, for the ambientpressure cubic spinel phase of magnetite with inverse electronic configuration in which tetrahedral sites are filled by $\mathrm{Fe}^{3+}$ ions and hence are already maximally charged, the possibility of an opposite electron transfer under pressure, from tetrahedral sites to the octahedral network has been suggested ${ }^{41}$. However, this conjecture was not in line with earlier work ${ }^{42}$, and was not confirmed in subsequent studies ${ }^{43-46}$. It was established for magnetite that its charge-ordered phase may be suppressed by applied pressure of about $8 \mathrm{GPa}^{47,48}$. Thus, the behavior of $\mathrm{Fe}_{4} \mathrm{O}_{5}$ is remarkably different from that of magnetite and demonstrates new perspectives for charge-ordered states in iron-rich oxides. At the moment, we cannot unambiguously ascertain the driving forces of the phase transitions observed in $\mathrm{Fe}_{4} \mathrm{O}_{5}$ both at ambient and high pressures. In previous work investigating the Verwey transition in magnetite, it was determined that the intersite Coulomb interactions between the $3 d$ electrons of the $\mathrm{Fe}$ ions alone, as well as phonon-driven lattice instability, could hardly stimulate this transition 49,50 . A more complex scenario, however, in which the strong electron correlations enhance the electron-phonon interactions and simultaneously reduce the mobility of the minority-spin $t_{2 g}$ electrons of $\mathrm{Fe}^{2+}$ ions, 
increasing their tendency towards localization, could be an indication that electron-phonon interactions may be a driving force of the Verwey transition ${ }^{49,50}$. The phase transitions in $\mathrm{Fe}_{4} \mathrm{O}_{5}$ could have similar or even more complex scenarios involving the charge, lattice, spin, and orbital degrees of freedom.

Mössbauer spectroscopy of $\mathrm{Fe}_{4} \mathrm{O}_{5}$ at low temperature under high pressure. At ambient conditions, the Mössbauer spectra of $\mathrm{Fe}_{4} \mathrm{O}_{5}$ can be well fitted by the superposition of a magnetic sextet and a paramagnetic doublet with relative areas of $80(2) \%$ and 20 (2)\%, respectively (Fig. 8c). The presence of the sextet component indicates the existence of magnetic order at room temperature. In the $\mathrm{Fe}_{4} \mathrm{O}_{5}$ crystal, $25 \%$ of iron cations occupy the trigonal prisms, and $75 \%$ have octahedral coordination (Fig. 1a). Hence, we can assign the doublet to prismatic Fel atoms, and likewise the sextet to octahedral $\mathrm{Fe} 2$ and $\mathrm{Fe} 3$ atoms. We determine the hyperfine parameters of these components. For example, for the spectrum collected at $295 \mathrm{~K}$ and $2.1 \mathrm{GPa}$, we determine the center shift of the doublet to be $\delta_{\mathrm{CS}}=1.125(12) \mathrm{mm} / \mathrm{s}$ and the quadrupole splitting to be $\Delta=1.93(2) \mathrm{mm} / \mathrm{s}$. For the sextet, we find the center shift to be $\delta_{\mathrm{CS}}=0.568(15) \mathrm{mm} / \mathrm{s}$, the quadrupole shift to be $\varepsilon=$ $0.21(1) \mathrm{mm} / \mathrm{s}$, and the hyperfine magnetic field to be $H_{\mathrm{hf}}=24.96$ (13) T. The center shift of the Mössbauer spectral components depends primarily on the oxidation state of iron in a linear-like manner. We compare these center shifts with those reported for other iron oxides, e.g., $\delta_{\mathrm{CS}}=0.36 \mathrm{~mm} / \mathrm{s}$ for octahedral $\mathrm{Fe}^{3+}$ ions in hematite $\left(\alpha-\mathrm{Fe}_{2} \mathrm{O}_{3}\right)^{51}$ and $\delta_{\mathrm{CS}}=0.67 \mathrm{~mm} / \mathrm{s}$ for octahedral mixed-valent $\mathrm{Fe}^{2.5+}$ ions in magnetite ${ }^{51}$. The linear trend based on these data suggests that octahedrally-coordinated $\mathrm{Fe}^{2+}$ ions should exhibit center shifts around $\delta_{\mathrm{CS}}=0.98 \mathrm{~mm} / \mathrm{s}$; likewise the above-determined value of $\delta_{\mathrm{CS}}=0.568 \mathrm{~mm} / \mathrm{s}$ for the magnetic sextet in $\mathrm{Fe}_{4} \mathrm{O}_{5}$ should correspond to an oxidation state of $\mathrm{Fe}^{2.67+}$, in excellent agreement with the BVS results (Fig. 1a). The large value of $\delta_{\mathrm{CS}}=1.125(12) \mathrm{mm} / \mathrm{s}$ for the Fel doublet unambiguously corresponds to $\mathrm{Fe}^{2+}$, in line with both BVS estimations (Fig. 1a) and earlier data for ferrous-iron compounds ${ }^{51}$

We note that the line widths of the sextet are roughly twice as large as those of the doublet ( 1.1 vs $0.5 \mathrm{~mm} / \mathrm{s}$ ) (Fig. $8 \mathrm{c}$ ). This broadening results from electron exchange between the $\mathrm{Fe}^{2+}$ and $\mathrm{Fe}^{3+}$ cations occupying the octahedral sites; a similar effect was also observed in magnetite ${ }^{52}$. Upon cooling, the doublet component loses intensity and completely disappears around $150 \mathrm{~K}$ (Fig. 8b). Hence, Fe1 atoms occupying the oxygen prisms become magnetically ordered, and their contribution to the spectra largely overlaps with the stronger signal of $\mathrm{Fe} 2$ and $\mathrm{Fe} 3$ atoms. The Mössbauer spectra demonstrate a pronounced broadening around $150 \mathrm{~K}$ (Fig. $8 \mathrm{~b}$ ), where a charge ordering in $\mathrm{Fe}_{4} \mathrm{O}_{5}$ was observed ${ }^{32}$.

For magnetite, it has been documented that charge ordering below the Verwey transition at $120 \mathrm{~K}$ leads to the appearance of many closely-overlapping magnetic sextets which can be resolved only under special conditions, such as single-crystal measurements in magnetic fields ${ }^{52,53}$. Here, we collect spectra from a polycrystalline $\mathrm{Fe}_{4} \mathrm{O}_{5}$ sample and, together with other factors like potential phase co-existence (Fig. 2), this impedes an unambiguous fitting of the Mössbauer spectra at low temperatures. A simple single-sextet analysis of the spectra shows that the quadrupole shift has a discontinuity in its temperature dependence between 150 and $100 \mathrm{~K}$ (Supplementary Figure $2 \mathrm{~b}$ and Supplementary Table 5). This feature is likely linked to changes in the magnetic properties (kink in inverse magnetic susceptibility in Fig. 7a).

The Mössbauer spectra collected in the charge-ordered states appear to be a superposition of several sextets. For instance, the spectrum acquired at $20 \mathrm{~K}$ and $2.6 \mathrm{GPa}$, i.e., in the stability region of the incommensurately-modulated $\mathrm{Fe}_{4} \mathrm{O}_{5}$-II phase with an infinite number of different environments for iron (Fig. 2), can be reasonably well described by three sextets (Fig. 8c). The center shifts of these sextets are about $0.6-0.85 \mathrm{~mm} / \mathrm{s}$, i.e., between $\delta_{\mathrm{CS}}=$ $0.36 \mathrm{~mm} / \mathrm{s}$ for $\mathrm{Fe}^{3+}$ ions in hematite $\mathrm{e}^{51}$ and $0.98 \mathrm{~mm} / \mathrm{s}$ estimated above for octahedral $\mathrm{Fe}^{2+}$ atoms, but at the same time quite far from both. We therefore conclude that in the charge-ordered phases of $\mathrm{Fe}_{4} \mathrm{O}_{5}$, the oxidation states of the octahedrally-coordinated iron did not split into $\mathrm{Fe}^{2+}$ and $\mathrm{Fe}^{3+}$ components, and hence, these ions are characterized by stable non-integer oxidation states. This finding is in line with the earlier conjecture ${ }^{4,32}$ that the minority-spin $t_{2 g}$ electron of $\mathrm{Fe}^{2+}$ ions is shared between all ions involved in the formation of either trimers or dimers.

We do not observe any noticeable changes in the spectra with pressure up to $8 \mathrm{GPa}$ at low temperatures. This fact indicates that $\mathrm{Fe}_{4} \mathrm{O}_{5}$-II and $\mathrm{Fe}_{4} \mathrm{O}_{5}$-III charge-ordered phases are not readily distinguishable by Mössbauer spectroscopy (Figs. 2 and 8c). With further compression to $16.3 \mathrm{GPa}$ across the beginning of the $\mathrm{Fe}_{4} \mathrm{O}_{5}$-III $\rightarrow \mathrm{Fe}_{4} \mathrm{O}_{5}$-IV transition (Fig. 2), the hyperfine field distribution changes to an apparent bimodal form (Supplementary Figure 2c). We fit these spectra by a superposition of two sextets (Fig. 8c), and for example, at $11.3 \mathrm{GPa}$ and $20 \mathrm{~K}$ in $\mathrm{Fe}_{4} \mathrm{O}_{5}$-III phase, their center shifts are $\delta_{\mathrm{CS}}=0.66(3)$ and 0.82 (3) $\mathrm{mm} / \mathrm{s}$. Taking into account the second-order Doppler shift (we use the value of $0.11 \mathrm{~mm} / \mathrm{s}$ for hematite) ${ }^{54}$ and disregarding a possible pressure correction for the $\delta_{\mathrm{CS}}$ values, we estimate the average oxidation states of iron linked to the green and purple sextets to be +2.7 and +2.45 , respectively (Fig. $8 \mathrm{c}$ ). Therefore, this case also unambiguously demonstrates that the oxidation states of the octahedrally-coordinated iron in $\mathrm{Fe}_{4} \mathrm{O}_{5}$ do not split into integer $\mathrm{Fe}^{2+}$ and $\mathrm{Fe}^{3+}$ components, even at $20 \mathrm{~K}$. These +2.7 and +2.45 values correspond well to the average BVS values for the iron cations occupying the single chains of $\mathrm{Fe} 2$ and double chains of Fe3 octahedra, respectively (Figs. 4 and 5).

Magnetic properties of $\mathrm{Fe}_{4} \mathrm{O}_{5}$. The magnetization data for $\mathrm{Fe}_{4} \mathrm{O}_{5}$ collected at ambient pressure (Fig. 8a) are similar to those reported earlier ${ }^{32}$, but show slightly smaller absolute values of susceptibility. In this work, we carry out measurements on several single crystals of $\mathrm{Fe}_{4} \mathrm{O}_{5}$, and likely, this discrepancy may be related to a minor ferromagnetic impurity which can potentially be present in the large polycrystalline sample examined earlier ${ }^{32}$. There are two main features of the magnetization data: (i) the transformation between canted and collinear magnetic ordering (around $90 \mathrm{~K}$ at ambient pressure), and (ii) charge ordering that manifests itself by a kink in the $1 / \chi$ curve (around $150 \mathrm{~K}$ at ambient pressure) (Fig. 8a). Both features are observed up to 1.83 $\mathrm{GPa}$, the maximum pressure of our measurement, and shift toward higher temperature upon compression. The size of the canted moment increases abruptly, with a large change between 0.66 and $0.90 \mathrm{GPa}$ and weak changes below or above this range. Given the observation of the $\mathrm{Fe}_{4} \mathrm{O}_{5}$-III phase at $200 \mathrm{~K}$ and $2 \mathrm{GPa}$ (Fig. 2), we conclude that our magnetization data extend well into its stability range, and hence, this abrupt change in the moment likely results from the phase transformation. Moreover, the kink in the $1 / \chi$ curves shifts to higher temperatures (Fig. 8a), in agreement with the positive slope of the $\mathrm{Fe}_{4} \mathrm{O}_{5}-\mathrm{I} \rightarrow \mathrm{Fe}_{4} \mathrm{O}_{5}$-III phase boundary. Above $0.90 \mathrm{GPa}$, the kink is strongly smeared out, probably because of more sluggish charge-ordering processes at the $\mathrm{Fe}_{4} \mathrm{O}_{5}-\mathrm{I} \rightarrow \mathrm{Fe}_{4} \mathrm{O}_{5}$-III phase transition, compared to $\mathrm{Fe}_{4} \mathrm{O}_{5^{-}}$ $\mathrm{I} \rightarrow \mathrm{Fe}_{4} \mathrm{O}_{5}-\mathrm{II}^{32}$.

The magnetization data reveal close similarities between $\mathrm{Fe}_{4} \mathrm{O}_{5}$-II and $\mathrm{Fe}_{4} \mathrm{O}_{5}$-III. Both support the formation of a canted state at low temperatures. Moreover, both charge-ordered phases emerge from the same collinear magnetic order that sets in around $320 \mathrm{~K}$ at ambient pressure ${ }^{32}$. As seen from the Mössbauer 

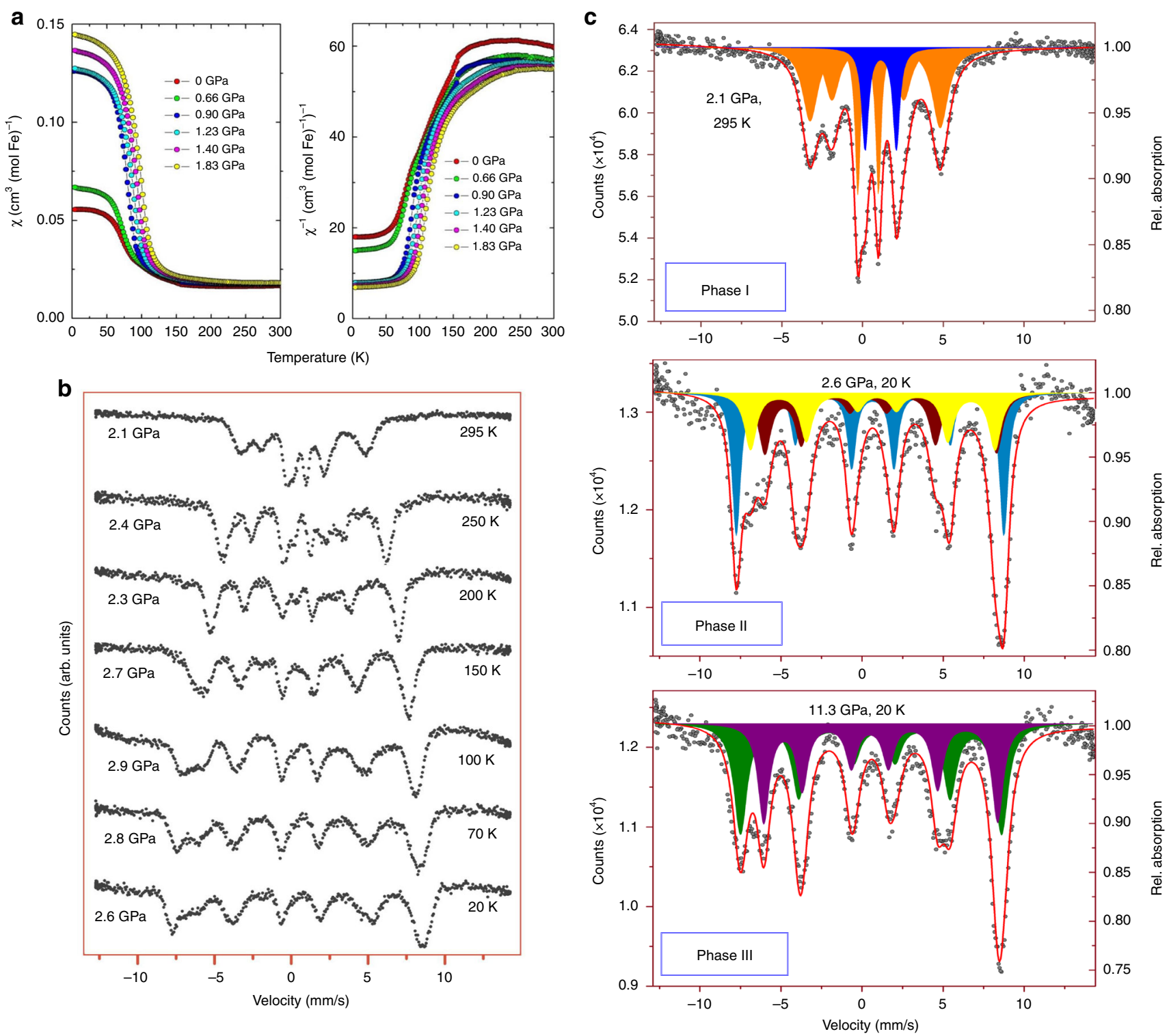

Fig. 8 Magnetic susceptibility and Mössbauer spectra of $\mathrm{Fe}_{4} \mathrm{O}_{5}$. a Temperature dependence of magnetic susceptibility and inverse magnetic susceptibility measured at different hydrostatic pressures in a field of $0.5 \mathrm{~T}$ under field cooling. b Evolution of Mössbauer spectra upon cooling at about 2-3 GPa. Broadening of the first (low-velocity) line of the sextet starting at $150 \mathrm{~K}$ indicates charge ordering. c Representative Mössbauer spectra of different phases of $\mathrm{Fe}_{4} \mathrm{O}_{5}$ collected at different pressures and temperatures. The spectrum of phase I can be refined by superposition of a paramagnetic doublet (blue) assigned to iron in the trigonal prisms and a magnetic sextet (orange) assigned to Fe in the octahedra in a mixed-valence state. The spectra of phases II and III exhibit a complex distribution of hyperfine fields and can be refined by superposition of sextets

spectra (Fig. 8b), the initial magnetic ordering remains above room temperature at these pressures. As established earlier ${ }^{32}$, a ferromagnetic spin alignment along the $a$-direction (in the coordinate framework of $\mathrm{Fe}_{4} \mathrm{O}_{5}-\mathrm{I}$ ) is essential for the formation of dimers and trimers in the charge-ordered state ${ }^{32}$, and hence magnetic ordering is a key prerequisite of the charge ordering. The same type of magnetic order would even support dimer formation in $\mathrm{Fe}_{4} \mathrm{O}_{5}$-IV. This demonstrates that this magnetic ordering can produce different charge-ordered states in a single structural framework.

Conclusions. We determined the low-temperature high-pressure phase diagram of $\mathrm{Fe}_{4} \mathrm{O}_{5}$ using single crystal X-ray diffraction and Mössbauer spectroscopy and by measurement of magnetic properties. We found two novel crystal structures of $\mathrm{Fe}_{4} \mathrm{O}_{5}$ and observed the extended regions of their co-existence in the phase diagram. A dramatic change in the charge-ordering pattern in the second high-pressure phase was attributed to electron hopping from the octahedral to the prismatic iron chains. We propose that the average oxidation state of the iron cations in oxides of this family can pre-determine a charge-ordering pattern. Thus, $\mathrm{Fe}_{4} \mathrm{O}_{5}$ demonstrates that the charge-ordering pattern can be changed by applied pressure or stress, and two or more charge-ordered phases can co-exist with each other inside one single crystal. Our work highlights the complexity of charge-ordering processes in iron-based and other transition metal oxides, but simultaneously it suggests a clue to these phenomena.

\section{Methods}

Sample preparation and characterization. The samples of $\mathrm{Fe}_{4} \mathrm{O}_{5}$ were synthesized in a 1200-tonne Multi-Anvil Press at BGI ${ }^{55}$ at HP-HT conditions from stoichiometric mixtures of fine powders of $\mathrm{Fe}_{3} \mathrm{O}_{4}$ (Aldrich, 99.99\% purity) and $\mathrm{Fe}$ (Aldrich, 99.999\% purity). The syntheses were performed at pressures of $14 \mathrm{GPa}$ over several hours. 
Polycrystalline samples were fabricated at synthesis temperatures of about $1100-1200{ }^{\circ} \mathrm{C}$, while higher temperatures $\left(1350-14500^{\circ} \mathrm{C}\right)$ enabled the growth of highquality single crystals with linear sizes of $20-200 \mu \mathrm{m}^{32}$. We employed a standard assembly including a Re cylindrical sample capsule, a $\mathrm{LaCrO}_{3}$ heater, a W3Re/W25Re thermocouple, and other components packed inside an octahedron made of 5\% $\mathrm{Cr}_{2} \mathrm{O}_{3}$-doped $\mathrm{MgO}^{56,57}$. The procedure was similar to that described in previous work ${ }^{58,59}$. The chemical composition of the samples was verified by means of scanning electron microscopy (SEM) using a LEO-1530 instrument and by microprobe analysis using a JEOL JXA-8200 electron microscope. The crystal structure of the samples was determined by means of single crystal and powder X-ray diffraction using a highbrilliance Rigaku diffractometer (Mo $K_{\alpha}$ radiation, $\lambda=0.7108 \AA$ ).

Single crystal X-ray diffraction under pressure. We selected high-quality single crystals of $\mathrm{Fe}_{4} \mathrm{O}_{5}$ and loaded them into symmetric membrane diamond anvil cells (DACs) equipped with Boehler-Almax diamonds that enabled X-ray diffraction images to be collected over the widest range of angles. We employed three DACs with diamond anvil culet sizes of 400 and $300 \mu \mathrm{m}$. Together with the sample in the same cell, we loaded a ruby sphere and a chip of gold that was used for pressure determination (Fig. 2). An additional ruby sphere was placed on the outer surface of one diamond anvil to monitor the reference of its $R_{1}$ line at low temperature and ambient pressure. All of the DACs were filled with Ne pressure-transmitting medium. In total, we carried out three high-pressure single crystal X-ray diffraction experiments. The first one served as an initial scanning of the low-temperature phase diagram of $\mathrm{Fe}_{4} \mathrm{O}_{5}$, and it was performed at the ID27 beamline of the European Synchrotron Radiation Facility (ESRF, Grenoble, France) with a wavelength of $\lambda=0.3738 \AA$. The second and third runs involved more detailed investigations, and they were accomplished in a cold-finger He cryostat on the P02.2 beamline at the Deutsches Elektronen-Synchrotron (DESY, Hamburg, Germany) using a wavelength of $\lambda=0.2887 \AA^{60}$. Additionally, we carried out a room temperature compression experiment with laser heating at high pressures on beamline ID09a at $\operatorname{ESRF}(\lambda=0.41513 \AA)$. At each $(P, T)$ point on the phase diagram, we acquired single-crystal X-ray diffraction images upon continuous rotation of the cell with the sample around the vertical $\omega$-axis with a step of $\Delta \omega=0.5^{\circ}$ and an exposure time of $t=0.5 \mathrm{~s} /$ frame. The diffraction data were collected by a Perkin Elmer XRD1621 detector. We analyzed these data with CrysAlisPro software, and solved the crystal structures using JANA2006 software ${ }^{61}$.

We analyze the $\mathrm{Fe}-\mathrm{O}$ bond lengths of all iron cations in the different crystal structures of $\mathrm{Fe}_{4} \mathrm{O}_{5}$ using a common BVS method ${ }^{36}$. In this method, a bond valence is determined as $\left(S_{i j}=\exp \left[\left(R_{i j}-d_{i j}\right) / b_{0}\right]\right.$, where $d_{i j}$ is the distance between atoms $i$ and $j, R_{i j}$ is the bond valence parameter (empirically determined distance for this cation-anion pair), and $b_{0}$ is an empirical parameter about $0.37 \AA$ ), and then, a BVS value of a cation is determined as a sum of individual bond valences $\left(V_{i}=\sum_{j} s_{i j}\right)^{36}$. In these calculations, we used $b_{0}=0.37 \AA$ and the bond-valence parameters $R_{i j}$ determined at ambient conditions for $\mathrm{Fe}^{2+}-\mathrm{O}$ and $\mathrm{Fe}^{3+}-\mathrm{O}$ bonds as 1.734 and $1.759 \AA$, respectively ${ }^{36}$. Using literature data from the equation of state of hematite $\left(\alpha-\mathrm{Fe}_{2} \mathrm{O}_{3}\right)$ determined from single crystal X-ray diffraction experiments up to $25 \mathrm{GPa}^{62}$, we estimated a pressure dependence of the bond-parameter $R_{i j}$ for the $\mathrm{Fe}^{3+}-\mathrm{O}$ bonds, and applied these values in the BVS estimations as well. Since the total cation charge in the formula unit $(+10)$ should be conserved at all pressures and temperatures, the calculated nominal BVS values were accordingly renormalized to meet this requirement. After performing these procedures, the calculations using different starting $R_{i j}$ values gave identical results within experimental uncertainty.

Mössbauer spectroscopy under pressure. For Mössbauer spectroscopic examination over a wide pressure-temperature range, we synthesized a polycrystalline sample of $20 \%{ }^{57} \mathrm{Fe}$-enriched $\mathrm{Fe}_{4} \mathrm{O}_{5}$. We also utilized a membrane DAC with diamond anvil culet sizes of $400 \mu \mathrm{m}$. The DAC was fixed inside a cryostat. We collected synchrotron Mössbauer source (SMS) ${ }^{63}$ spectra on the Nuclear Resonance beamline ID18 at ESRF ${ }^{64}$. The SMS is based on a nuclear resonant monochromator employing pure nuclear reflections of an iron borate $\left({ }^{57} \mathrm{FeBO}_{3}\right)$ crystal. The source provides ${ }^{57} \mathrm{Fe}$ resonant radiation at $14.4 \mathrm{keV}$ within a bandwidth of $15 \mathrm{neV}$, which is tunable in energy over a range of $\sim \pm 0.6 \mathrm{meV}^{63}$. The beam of gamma-radiation emitted by the SMS was focused to a $10 \times 15 \mu \mathrm{m}^{2}$ spot size. The velocity scale was calibrated relative to a natural $\alpha$-Fe foil of $25 \mu \mathrm{m}$ thickness. The center shift values are given relative to $\alpha$-Fe. We monitored the width and the absolute position of the isomer shift of the source line before and after each measurement using a $\mathrm{K}_{2} \mathrm{Mg}^{57} \mathrm{Fe}(\mathrm{CN})_{6}$ reference single line absorber.

Magnetic measurements under pressure. The bulk magnetization measurements under hydrostatic pressure ${ }^{65,66}$ were performed in a CuBe pressure cell placed inside a Quantum Design MPMS 5S SQUID magnetometer. Daphne 7373 oil was used as a pressure-transmitting medium. One small piece of lead $(\sim 0.1 \mathrm{mg})$ was placed together with the sample inside the pressure cell, while another piece $(\sim 0.1 \mathrm{mg})$ was placed outside the pressure cell. Under pressure, the superconducting transition temperature of the inner piece decreases. The difference between the superconducting transition temperatures of the two lead samples determines the pressure value inside the pressure cell at low temperatures. Several small single crystals of $\mathrm{Fe}_{4} \mathrm{O}_{5}$ with a total mass of $\sim 0.6 \mathrm{mg}$ were placed into a gasket of the pressure cell along with the aforementioned piece of lead. The empty cell background data was subtracted ${ }^{65}$ using an automatic background subtraction (ABS) procedure. Field-cooling measurements of the lead and $\mathrm{Fe}_{4} \mathrm{O}_{5}$ samples were performed in fields of $2 \mathrm{mT}$ and $0.5 \mathrm{~T}$, respectively, from $300 \mathrm{~K}$ down to $4 \mathrm{~K}$.

\section{Data availability}

The X-ray crystallographic information files (CIFs) for structures that support the findings of this study have been deposited at the Inorganic Crystal Structure Database (ICSD) with accession codes 434152, 434153, 434154, 434155, and 434156 (http://www2. fiz-karlsruhe.de/icsd_home.html). The authors declare that all other data supporting the findings of this study are available within the article and Supplementary Information files, and also are available from the corresponding author upon reasonable request.

Received: 1 February 2018 Accepted: 31 August 2018

Published online: 08 October 2018

\section{References}

1. Faivre, D. (ed.) Iron Oxides: From Nature to Applications (Wiley-VCH, Weinheim, 2016).

2. Verwey, E. J. W. Electronic conduction of magnetite $\left(\mathrm{Fe}_{3} \mathrm{O}_{4}\right)$ and its transition point at low temperatures. Nature 144, 327-328 (1939).

3. Lee, S. et al. Electrically driven phase transition in magnetite nanostructures. Nat. Mater. 7, 130-133 (2008).

4. Senn, M. R., Wright, J. P. \& Attfield, J. P. Charge order and three-site distortions in the Verwey structure of magnetite. Nature 481, 173-176 (2012).

5. Perversi, G., Cumby, J., Pachoud, E., Wright, J. P. \& Attfield, J. P. The Verwey structure of a natural magnetite. Chem. Commun. 52, 4864-4867 (2016).

6. de Jong, S. et al. Speed limit of the insulator-metal transition in magnetite. Nat. Mater. 12, 882-886 (2013).

7. Huang, H. Y. et al. Jahn-Teller distortion driven magnetic polarons in magnetite. Nat. Commun. 8, 15929 (2017).

8. Cumby, J. \& Attfield, J. P. Ellipsoidal analysis of coordination polyhedra. Nat. Commun. 8, 14235 (2017)

9. Karen, P. et al. Verwey transition in mixed-valence $\mathrm{TbBaFe}_{2} \mathrm{O}_{5}$ : two attempts to order charges. Phys. Rev. B 64, 214405 (2001).

10. Pratt, D. K. et al. Checkerboard to stripe charge ordering transition in $\mathrm{TbBaFe}_{2} \mathrm{O}_{5}$. Phys. Rev. B 87, 045127 (2013).

11. Long, Y. W. et al. Temperature-induced $A-B$ intersite charge transfer in an A-site-ordered $\mathrm{LaCu}_{3} \mathrm{Fe}_{4} \mathrm{O}_{12}$ perovskite. Nature 458, 60-63 (2009).

12. Lavina, B. et al. Discovery of the recoverable high-pressure iron oxide $\mathrm{Fe}_{4} \mathrm{O}_{5}$. Proc. Natl Acad. Sci. USA 108, 17281-17285 (2011).

13. Woodland, A. B., Frost, D. J., Trots, D. M., Klimm, K. \& Mezouar, M. In situ observation of the breakdown of magnetite $\left(\mathrm{Fe}_{3} \mathrm{O}_{4}\right)$ to $\mathrm{Fe}_{4} \mathrm{O}_{5}$ and hematite at high pressures and temperatures. Am. Mineral. 97, 1808-1811 (2012).

14. Lavina, B. \& Meng, Y. Unraveling the complexity of iron oxides at high pressure and temperature: synthesis of $\mathrm{Fe}_{5} \mathrm{O}_{6}$. Sci. Adv. 1, e1400260 (2015).

15. Myhill, R. et al. On the $P-T-f O_{2}$ stability of $\mathrm{Fe}_{4} \mathrm{O}_{5}, \mathrm{Fe}_{5} \mathrm{O}_{6}$ and $\mathrm{Fe}_{4} \mathrm{O}_{5}$-rich solid solutions. Contrib. Mineral. Petrol. 171, 51 (2016).

16. Merlini, M., Hanfland, M., Salamat, A., Petitgirard, S. \& Müller, H. The crystal structures of $\mathrm{Mg}_{2} \mathrm{Fe}_{2} \mathrm{C}_{4} \mathrm{O}_{13}$, with tetrahedrally coordinated carbon, and $\mathrm{Fe}_{13} \mathrm{O}_{19}$, synthesized at deep mantle conditions. Am. Mineral. 100, 2001-2004 (2015).

17. Bykova, E. et al. Structural complexity of simple $\mathrm{Fe}_{2} \mathrm{O}_{3}$ at high pressures and temperatures. Nat. Commun. 7, 10661 (2016).

18. Weerasinghe, G. L., Pickard, C. J. \& Needs, R. J. Computational searches for iron oxides at high pressures. J. Phys. Condens. Matter 27, 455501 (2015).

19. $\mathrm{Hu}$, Q. et al. $\mathrm{FeO}_{2}$ and $\mathrm{FeOOH}$ under deep lower-mantle conditions and earth's oxygen-hydrogen cycles. Nature 534, 241-244 (2016).

20. Jang, G., Kim, D. Y. \& Shim, J. H. Metal-insulator transition and the role of electron correlation in $\mathrm{FeO}_{2}$. Phys. Rev. B 95, 075144 (2017).

21. Zhang, X.-L., Niu, Z.-W., Tang, M., Zhao, J.-Z. \& Cai, L.-C. First-principles thermoelasticity and stability of pyrite-type $\mathrm{FeO}_{2}$ under high pressure and temperature. J. Alloys Compd. 719, 42-46 (2017).

22. Sinmyo, R. et al. Discovery of $\mathrm{Fe}_{7} \mathrm{O}_{9}$ : a new iron oxide with a complex monoclinic structure. Sci. Rep. 6, 32852 (2016).

23. Tuček, J. et al. Zeta- $\mathrm{Fe}_{2} \mathrm{O}_{3}$-a new stable polymorph in iron(III) oxide family. Sci. Rep. 5, 15091 (2015).

24. Evrard, $\mathrm{O}$. et al. Mise en evidence de $\mathrm{CaFe}_{4} \mathrm{O}_{6}$ et détermination des structures cristallines des ferrites de calcium $\mathrm{CaFe}_{2+n} \mathrm{O}_{4+n}(n=1,2,3)$ : un nouvel exemple d'intercroissance. J. Solid State Chem. 35, 112-119 (1980).

25. Delacotte, C. et al. Morin-like spin canting in the magnetic $\mathrm{CaFe}_{5} \mathrm{O}_{7}$ ferrite: a combined neutron and Mössbauer study. J. Solid State Chem. 247, 13-19 (2017).

26. Woodland, A. B. et al. $\mathrm{Fe}_{4} \mathrm{O}_{5}$ and its solid solutions in several simple systems. Contrib. Mineral. Petrol. 166, 1677-1686 (2013). 
27. Ishii, T. et al. High-pressure phase transitions in $\mathrm{FeCr}_{2} \mathrm{O}_{4}$ and structure analysis of new post-spinel $\mathrm{FeCr}_{2} \mathrm{O}_{4}$ and $\mathrm{Fe}_{2} \mathrm{Cr}_{2} \mathrm{O}_{5}$ phases with meteoritical and petrological implications. Am. Mineral. 99, 1788-1797 (2014).

28. Guignard, J. \& Crichton, W. A. Synthesis and recovery of bulk $\mathrm{Fe}_{4} \mathrm{O}_{5}$ from magnetite, $\mathrm{Fe}_{3} \mathrm{O}_{4}$. A member of a self-similar series of structures for the lower mantle and transition zone. Mineral. Mag. 78, 361-371 (2014).

29. Ballaran, T. B., Uenver-Thiele, L. \& Woodland, A. B. Complete substitution of $\mathrm{Fe}^{2+}$ by $\mathrm{Mg}$ in $\mathrm{Fe}_{4} \mathrm{O}_{5}$ : the crystal structure of the $\mathrm{Mg}_{2} \mathrm{Fe}_{2} \mathrm{O}_{5}$ end-member. $A m$. Mineral. 100, 628-631 (2015).

30. Hong, K. H., McNally, G. M., Coduri, M. \& Attfield, J. P. Synthesis, crystal structure, and magnetic properties of $\mathrm{MnFe}_{3} \mathrm{O}_{5}$. Z. Anorg. Allg. Chem. 642, 1355-1358 (2016).

31. Siersch, N. C., Ballaran, T. B., Uenver-Thiele, L. \& Woodland, A. B. Compressibility and high-pressure structural behaviour of $\mathrm{Mg}_{2} \mathrm{Fe}_{2} \mathrm{O}_{5}$. Am. Mineral. 102, 845-850 (2017).

32. Ovsyannikov, S. V. et al. Charge ordering transition in iron oxide $\mathrm{Fe}_{4} \mathrm{O}_{5}$ involving competing dimer and trimer formation. Nat. Chem. 8, 501-508 (2016).

33. Ziatdinov, M. et al. Atomic-scale observation of structural and electronic orders in the layered compound alpha- $\mathrm{RuCl}_{3}$. Nat. Commun. 7, 13774 (2016).

34. Bykov, M. et al. Spin-Peierls distortions in $\mathrm{TiPO}_{4}$. Phys. Rev. B 88, 184420 (2013).

35. Bykov, M. et al. High-pressure phase transformations in $\mathrm{TiPO}_{4}$ : a route to pentacoordinated phosphorus. Angew. Chem. Int. Ed. 55, 15053-15057 (2016).

36. Brese, N. E. \& O'Keffee, M. Bond-valence parameters for solids. Acta Crystallogr. B47, 192-197 (1991).

37. Murnaghan, F. D. The compressibility of media under extreme pressures. Proc. Natl Acad. Sci. USA 30, 244-247 (1944).

38. Birch, F. Finite elastic strain of cubic crystals. Phys. Rev. 71, 809-824 (1947).

39. Kothapalli, K. et al. Nuclear forward scattering and first-principles studies of the iron oxide phase $\mathrm{Fe}_{4} \mathrm{O}_{5}$. Phys. Rev. B 90, 024430 (2014).

40. Friend, R. H. \& Yoffe, A. D. Electronic properties of intercalation complexes of the transition metal dichalcogenides. Adv. Phys. 36, 1-94 (1987).

41. Rozenberg, G. Kh et al. Structural characterization of temperature- and pressure-induced inverse $\leftrightarrow$ normal spinel transformation in magnetite. Phys. Rev. B 75, 020102(R) (2007).

42. Haavik, C., Stolen, S., Fjellvag, H., Hanfland, M. \& Hausermann, D. Equation of state of magnetite and its high-pressure modification: thermodynamics of the Fe-O system at high pressure. Am. Mineral. 85, 514-523 (2000).

43. Klotz, S. et al. Magnetism and the Verwey transition in $\mathrm{Fe}_{3} \mathrm{O}_{4}$ under pressure. Phys. Rev. B 77, 012411 (2008).

44. Gilder, S. A. \& Le Goff, M. Systematic pressure enhancement of titanomagnetite magnetization. Geophys. Res. Lett. 35, L10302 (2008)

45. Ovsyannikov, S. V., Shchennikov, V. V., Todo, S. \& Uwatoko, Y. A new crossover in $\mathrm{Fe}_{3} \mathrm{O}_{4}$ magnetite under pressure near $6 \mathrm{GPa}$ : modification to "ideal" inverse cubic spinel? J. Phys. Condens. Matter 20, 172201 (2008).

46. Ebad-Allah, J. et al. Pressure dependence of the Verwey transition in magnetite: an infrared spectroscopic point of view. J. Appl. Phys. 112, 073524 (2012).

47. Todo, S., Takeshita, N., Kanehara, T., Mori, T. \& Mori, N. Metallization of magnetite $\left(\mathrm{Fe}_{3} \mathrm{O}_{4}\right)$ under high pressure. J. Appl. Phys. 89, 7347-7349 (2001).

48. Rozenberg, G. Kh. et al. Origin of the Verwey transition in magnetite. Phys. Rev. Lett. 96, 045705 (2006).

49. Piekarz, P., Parlinski, K. \& Oleś, A. M. Mechanism of the Verwey transition in magnetite. Phys. Rev. Lett. 97, 156402 (2006).

50. Piekarz, P., Parlinski, K. \& Oleś, A. M. Origin of the Verwey transition in magnetite: group theory, electronic structure, and lattice dynamics study. Phys. Rev. B 76, 165124 (2007).

51. Menil, F. Systematic trends of the ${ }^{57} \mathrm{Fe}$ Mössbauer isomer shifts in $\left(\mathrm{FeO}_{n}\right)$ and $\left(\mathrm{FeF}_{n}\right)$ polyhedra. Evidence of a new correlation between the isomer shift and the inductive effect of the competing bond $T-X(\rightarrow \mathrm{Fe})$ (where $X$ is $\mathrm{O}$ or $\mathrm{F}$ and $T$ any element with a formal positive charge). J. Phys. Chem. Solids 46, 763-789 (1985).

52. Hargrove, R. S. \& Kundig, W. Mössbauer measurements of magnetite below the Verwey transition. Solid State Commun. 8, 303-308 (1970).

53. Berry, F. J., Skinner, S. \& Thomas, M. F. ${ }^{57}$ Fe Mossbauer spectroscopic examination of a single crystal of $\mathrm{Fe}_{3} \mathrm{O}_{4}$. J. Phys. Condens. Matter 10, 215-220 (1998).

54. Sturhahn, W. \& Chumakov, A. Lamb-Mössbauer factor and second-order Doppler shift from inelastic nuclear resonant absorption. Hyperfine Interact. 123, 809-824 (1999)

55. Frost, D. J. et al. A new large-volume multianvil system. Phys. Earth Planet. Inter. 143-144, 507-514 (2004).

56. Ovsyannikov, S. V. et al. Structural and magnetic transitions in $\mathrm{CaCo}_{3} \mathrm{~V}_{4} \mathrm{O}_{12}$ perovskite at extreme conditions. Inorg. Chem. 56, 6251-6263 (2017).
57. Ovsyannikov, S. V. et al. Bulk silicon crystals with the high boron content, $\mathrm{Si}_{1-\mathrm{x}} \mathrm{B}_{\mathrm{x}}$ : two semiconductors form an unusual metal. Chem. Mater. 26 5274-5281 (2014)

58. Ovsyannikov, S. V. et al. Perovskite-like $\mathrm{Mn}_{2} \mathrm{O}_{3}$ : a path to new manganites. Angew. Chem. Int. Ed. 52, 1494-1498 (2013).

59. Ovsyannikov, S. V. et al. Hard oxide semiconductor with a direct and narrow bandgap and switchable $p-n$ electrical conduction. Adv. Mater. 26, 8185-8191 (2014).

60. Liermann, H.-P. et al. The extreme conditions beamline P02.2 and the extreme conditions science infrastructure at PETRA III. J. Synchrotron Radiat. 22, 908-924 (2015).

61. Petricek, V., Dusek, M. \& Palatinus, L. Crystallographic computing system JANA2006: general features. Z. Krist. 229, 345-352 (2014).

62. Schouwink, P. et al. High-pressure structural behavior of $\alpha-\mathrm{Fe}_{2} \mathrm{O}_{3}$ studied by single-crystal X-ray diffraction and synchrotron radiation up to $25 \mathrm{GPa}$. Am. Mineral. 96, 1781-1786 (2011).

63. Potapkin, V. et al. The ${ }^{57} \mathrm{Fe}$ synchrotron Mössbauer source at the ESRF. J. Synchrotron Radiat. 19, 559-569 (2012).

64. Rüffer, R. \& Chumakov, A. I. Nuclear resonance beamline at ESRF. Hyperfine Interact. 97-98, 589-604 (1996).

65. Tateiwa, N., Haga, Y., Fisk, Z. \& Onuki, Y. Miniature ceramic-anvil highpressure cell for magnetic measurements in a commercial superconducting quantum interference device magnetometer. Rev. Sci. Instrum. 82, 053906 (2011).

66. Tateiwa, N. et al. Improved sensitivity of magnetic measurements under high pressure in miniature ceramic anvil cell for a commercial SQUID magnetometer. Rev. Sci. Instrum. 84, 046105 (2013).

\section{Acknowledgements}

We acknowledge the ESRF for the provision of beam time at ID09a, ID18, and ID27. We also acknowledge the Sample Environment Service-HP lab and J. Jacobs for technical support of the loan pool diamond anvil cells. The authors thank D. Vasiukov for contributions to the refinement of the Mössbauer spectra and their interpretation. The authors thank M. Mezouar, G. Garbarino, and A. Cairns for assistance in the structural experiments at ID27 of ESRF (Grenoble, France). S.V.O. acknowledges the financial support of the Deutsche Forschungsgemeinschaft (DFG, project \# OV-110/3-1). A.A.T. was supported by the Federal Ministry for Education and Research through the Sofja Kovalevskaya Award of the Alexander von Humboldt Foundation.

\section{Author contributions}

S.V.O. synthesized and characterized the samples. S.V.O., M.B., E.B., K.G., A.V.K., A.S.P. and I.C. performed X-ray diffraction experiments. S.V.O., V.C., I. Kupenko, I. Kantor, A.I. C., R.R., C.M. and L.S.D. performed Mössbauer spectroscopic studies. R.S.M. and A.A.T. performed magnetic measurements and contributed to manuscript writing. M.B. solved the crystal structures and contributed to manuscript writing. S.V.O. wrote a first draft of the manuscript, and all of the co-authors read, revised, and commented on all of the versions. S.V.O. and L.S.D. initiated and designed the research.

\section{Additional information}

Supplementary Information accompanies this paper at https://doi.org/10.1038/s41467 018-06457-x.

Competing interests: The authors declare no competing interests.

Reprints and permission information is available online at http://npg.nature.com/ reprintsandpermissions/

Publisher's note: Springer Nature remains neutral with regard to jurisdictional claims in published maps and institutional affiliations.

Open Access This article is licensed under a Creative Commons Attribution 4.0 International License, which permits use, sharing, adaptation, distribution and reproduction in any medium or format, as long as you give appropriate credit to the original author(s) and the source, provide a link to the Creative Commons license, and indicate if changes were made. The images or other third party material in this article are included in the article's Creative Commons license, unless indicated otherwise in a credit line to the material. If material is not included in the article's Creative Commons license and your intended use is not permitted by statutory regulation or exceeds the permitted use, you will need to obtain permission directly from the copyright holder. To view a copy of this license, visit http://creativecommons.org/ licenses/by/4.0/.

(C) The Author(s) 2018 